\title{
Impairment of pH Gradient and Membrane Potential Mediates Redox Dysfunction in the Mitochondria of the Post-ischemic Heart
}

\author{
Patrick T. Kang, Chwen-Lih Chen, Paul Lin, William M. Chilian, and Yeong-Renn Chen \\ Department of Integrative Medical Sciences, College of Medicine, Northeast Ohio Medical \\ University, Rootstown, Ohio, USA, 44272
}

\section{Abstract}

The mitochondrial electrochemical gradient $(\Delta p)$, which comprises the $\mathrm{pH}$ gradient $(\Delta \mathrm{pH})$ and the membrane potential $(\Delta \Psi)$, is crucial in controlling energy transduction. During myocardial ischemia and reperfusion (IR), mitochondrial dysfunction mediates superoxide $\left({ }^{\circ} \mathrm{O}_{2}^{-}\right)$and $\mathrm{H}_{2} \mathrm{O}_{2}$ overproduction leading to oxidative injury. However, the role of $\Delta \mathrm{pH}$ and $\Delta \Psi$ in post-ischemic injury is not fully established. Here we studied mitochondria from the risk region of rat hearts subjected to $30 \mathrm{~min}$ of coronary ligation and $24 \mathrm{~h}$ of reperfusion in vivo. In the presence of glutamate, malate and ADP, normal mitochondria (mitochondria of non-ischemic region, NR) exhibited a heightened state 3 oxygen consumption rate (OCR) and reduced ${ }^{\circ} \mathrm{O}_{2}{ }^{-}$and $\mathrm{H}_{2} \mathrm{O}_{2}$ production when compared to state 2 conditions. Oligomycin (increases $\Delta \mathrm{pH}$ by inhibiting ATP synthase) increased ${ }^{\circ} \mathrm{O}_{2}{ }^{-}$and $\mathrm{H}_{2} \mathrm{O}_{2}$ production in normal mitochondria, but not significantly in the mitochondria of the risk region (IR mitochondria or post-ischemic mitochondria), indicating that normal mitochondrial ${ }^{\circ} \mathrm{O}_{2}{ }^{-}$and $\mathrm{H}_{2} \mathrm{O}_{2}$ generation is dependent on $\Delta \mathrm{pH}$ and that IR impaired the $\Delta \mathrm{pH}$ of normal mitochondria. Conversely, nigericin (dissipates $\Delta \mathrm{pH}$ ) dramatically reduced ${ }^{\circ} \mathrm{O}_{2}{ }^{-}$ and $\mathrm{H}_{2} \mathrm{O}_{2}$ generation by normal mitochondria under state 4 conditions, and this nigericin quenching effect was less pronounced in IR mitochondria. Nigericin also increased mitochondrial OCR, and predisposed normal mitochondria to a more oxidized redox status assessed by increased oxidation of cyclic hydroxylamine, CM-H. IR mitochondria, although more oxidized than normal mitochondria, were not responsive to nigericin-induced $\mathrm{CM}-\mathrm{H}$ oxidation, which is consistent with the result that IR induced $\Delta \mathrm{pH}$ impairment in normal mitochondria. Valinomycin, a $\mathrm{K}^{+}$ionophore used to dissipate $\Delta \Psi$, drastically diminished ${ }^{\circ} \mathrm{O}_{2}{ }^{-}$and $\mathrm{H}_{2} \mathrm{O}_{2}$ generation by normal mitochondria, but less pronounced effect on IR mitochondria under state 4 conditions, indicating that $\Delta \Psi$ also contributed to ${ }^{\circ} \mathrm{O}_{2}{ }^{-}$generation by normal mitochondria and that IR mediated $\Delta \Psi$ impairment. However, there was no significant difference in valinomycin-induced CM-H oxidation between normal and IR mitochondria. In conclusion, under normal conditions the proton backpressure imposed by $\Delta \mathrm{pH}$ restricts electron flow, controls a limited amount of ${ }^{\circ} \mathrm{O}_{2}{ }^{-}$generation, and results in a more reduced myocardium; however, IR causes $\Delta \mathrm{pH}$ impairment and prompts a more oxidized myocardium.

\footnotetext{
*Corresponding Author: Yeong-Renn Chen, Ph.D., Department of Integrative Medical Sciences, College of Medicne, Northeast Ohio Medical University, 4209 State Route 44, PO Box 95, Rootstown, OH 44272, ychen1 @ neomed.edu.

Disclosure

On behalf of all authors, the corresponding author states that there is no conflict of interest.
} 


\section{Keywords}

myocardial ischemia and reperfusion; mitochondria; redox dysfunction; $\mathrm{pH}$ gradient; membrane potential

\section{INTRODUCTION}

Mitochondrial dysfunction is the major contributor to myocardial ischemia/reperfusion injury. The investigations into reactive oxygen species (ROS) generation by mitochondria during ischemia and reperfusion have been extensively reviewed [7, 35]. Cardiac ischemia puts the myocardium into the physiological conditions of hypoxia, substrate deprivation, and acidosis. Mitochondria are thus situated in a highly reductive environment with low $\mathrm{pO}_{2}$ (oxygen tension) and low ADP. In the ischemic heart, oxygen delivery to the myocardium is not sufficient to meet the needs of mitochondrial oxidative metabolism. Re-introduction of oxygen upon reperfusion induces marked hyperoxygenation in the myocardium [42], and greatly increases electron leakage from the mitochondrial electron transport chain (ETC), leading to overproduction of ${ }^{\bullet} \mathrm{O}_{2}^{-}$and ${ }^{\circ} \mathrm{O}_{2}^{-}$-derived oxidants in the mitochondria $[1,11]$.

The proton motive force ( $\Delta p$, or electrochemical gradient) across the inner mitochondrial membrane is generated from proton pumping and represents the potential energy driving proton re-entry to the matrix for ATP synthesis. The $\Delta p$ consists of a proton gradient $(\Delta \mathrm{pH})$ and a membrane potential $(\Delta \Psi)$, which potentially contributes to ${ }^{\circ} \mathrm{O}_{2}{ }^{-}$production mediated by mitochondria. In vitro studies have firmly established the effect of $\Delta \Psi$ on ${ }^{\circ} \mathrm{O}_{2}{ }^{-}$ production by mitochondrial complex III, and this result led to the suggestion that cells modulate the magnitude of mitochondrial proton motive force to protect the mitochondria from excess production of ${ }^{\bullet} \mathrm{O}_{2}{ }^{-}[34]$.

Earlier studies with isolated mitochondria of rat and murine hearts indicated that mitochondria produce large amount of ${ }^{\bullet} \mathrm{O}_{2}^{-}$under oligomycin-induced state 4 conditions, but ${ }^{\circ} \mathrm{O}_{2}{ }^{-}$generation is diminished under conditions of ADP-mediated state 3 and FCCPmediated uncoupling $[20,22]$. The results thus lend support to the hypothesis that the proton motive force is high, and substantially contributes to ${ }^{\circ} \mathrm{O}_{2}{ }^{-}$production when the activity of $\mathrm{F}_{1} \mathrm{~F}_{0}$ ATP synthase $\left(\mathrm{F}_{1} \mathrm{~F}_{0}\right.$ ATPase) is low (state 2 conditions) or $\mathrm{F}_{1} \mathrm{~F}_{0}$ ATPase is inhibited (state 4 conditions). Restoration of ATP synthesis (state 3 conditions) via oxidative phosphorylation diminishes the $\Delta \mathrm{pH}$ and $\Delta \Psi$, thus greatly reducing ${ }^{\circ} \mathrm{O}_{2}{ }^{-}$generation.

Studies with mouse hearts have indicated that ischemia can depolarize $\Delta \Psi$, which is directly correlated to the decreased reverse electron flow-induced ROS production by ischemiadamaged mitochondria, and indirectly supports the role of $\Delta \Psi$ in complex I-mediated ${ }^{\circ} \mathrm{O}_{2}{ }^{-}$ generation [33]. In the disease model of myocardial ischemia and reperfusion injury, oxidative damage to the ETC is marked in the region of myocardial infarction [5, 25]. Studies have further demonstrated that redox-dependent alterations of ETC and $\mathrm{F}_{1} \mathrm{~F}_{0}$ ATPase in the post-ischemic myocardium are involved in oxidative post-translational modifications, including increasing protein tyrosine nitration of complex I, complex III, and $\mathrm{F}_{1} \mathrm{~F}_{0}$ ATPase [29], increasing protein tyrosine nitration of complex II [2], increasing protein Sglutathionylation of complex I [3], and increasing protein sulfonation and disulfide 
formation of complex II [39], suggesting a redox-dependent dysfunction in the mitochondria of the post-ischemic heart. The results logically lend support to the hypothesis that oxidative injury of ETC and $\mathrm{F}_{1} \mathrm{~F}_{0}$ ATPase can weaken the proton motive force, which further mediates the redox dysfunction in the post-ischemic heart. In the current study, we attempt to establish the roles of $\Delta \mathrm{pH}$ and $\Delta \Psi$ in post-ischemic injury by isolated mitochondria from a disease model of in vivo myocardial ischemia and reperfusion, followed by determining the rate of ${ }^{\bullet} \mathrm{O}_{2}{ }^{-}$production, $\mathrm{H}_{2} \mathrm{O}_{2}$ generation, and redox activity using EPR spin probes. Our findings indicated that the proton backpressure imposed by mitochondrial $\Delta \mathrm{pH}$ and $\Delta \Psi$ can restrict electron flow and result in a more reduced myocardium environment, which modulates electron leakage for ${ }^{\circ} \mathrm{O}_{2}{ }^{-}$and $\mathrm{H}_{2} \mathrm{O}_{2}$ generation (which functions as a physiological signaling molecule). Conversely, ischemia and reperfusion injury (IR) causes $\Delta p$ impairment, destroys physiological control of electron leakage by the ETC, and prompts the myocardium to become a more oxidized environment.

\section{MATERIALS AND METHODS}

\section{Animals}

Male Sprague-Dawley rats were purchased from Harlan (Indianapolis, IN; $\sim 300 \mathrm{~g}$ and 8 weeks old), rats were quarantined for one week prior to the surgical procedure of in vivo occlusion. The SOD2-tg mice ( 27-33 g and 12 weeks old) were obtained from the Jackson Laboratory. All procedures were performed with the approval (protocol no. 15-028) of the Institutional Animal Care and Use Committee (IACUC) at Northeast Ohio Medical University (Rootstown, $\mathrm{OH}$ ) and conformed to the Guide for the Care and Use of Laboratory Animals as adopted and promulgated by the NIH.

\section{Reagents}

Ammonium sulfate, diethylenetriaminepentaacetic acid (DTPA), ubiquinone-2 $\left(\mathrm{Q}_{2}\right)$, deoxycholic acid, FCCP (carbonylcyanide- $p$-trifluoromethoxyphenylhydrazone), oligomycin, nigericin, valinomycin, gramicidin (a polypeptide antibiotic of channel-forming ionophores that conduct ions through diffusion and destroy the $\Delta \Psi$ derived from the ion gradient), and polyethylene glycol superoxide dismutase (PEG-SOD) were purchased from Sigma-Aldrich Chemical Company (St. Louis, MO) and used as received. The spin probe of CM-H, 1-hydroxy-3-methoxycarbonyl-2,2,5,5-tetramethylpyrrolidine.HCl, was purchased from Enzo Life Sciences Inc. (Farmingdale, NY). The DMPO spin trap was purchased from Dojindo Molecular Technologies, Inc. (Rockville, MD), and stored under argon at $-80{ }^{\circ} \mathrm{C}$ until needed.

\section{Myocardial Infarction Model}

The procedure to produce a myocardial infarct involved an in vivo ischemia-reperfusion rat heart model $[2,6,16,41,42]$. Sprague-Dawley rats ( 300-350 g and 9-10 weeks old) were anesthetized with isoflurane ((2-chloro-2-(difluoromethoxy)-1,1,1-trifluoro-ethane)) via inhalation. After the rats were fully anesthetized, they were intubated and then ventilated with room air $(1.0 \mathrm{~mL} / 100 \mathrm{~g} / \mathrm{min}$, rate of $75-85$ breaths $/ \mathrm{min})$ using a mechanical ventilator Model 683 (Harvard Apparatus, Holliston, Massachusetts). The rats then underwent a left lateral thoracotomy, the pericardium was opened, and a pericardial cradle formed to allow 
adequate exposure of the heart surface. The left anterior descending coronary artery (LAD) was then occluded by placing a suture (6.0 nylon) around the origin of the LAD (illustrated in the Scheme 1A of enclosed box inset).

After $30 \mathrm{~min}$ of ischemia, the ligature around the coronary artery was removed, allowing reperfusion. Following the reperfusion, all wounds were closed and injected with buprenophine $(0.05 \mathrm{mg} / \mathrm{kg}, \mathrm{SQ})$. The muscular layers and skin incisions were closed with 4.0 nylon sutures.

Upon spontaneous breathing, the animal was allowed to recover and a physiological assessment was performed. During the recovery period the animals received supportive postoperative care as needed. Body temperature was maintained at $37^{\circ} \mathrm{C}$ by a thermal heating pad. By 6-h post-operation, the animals had recovered sufficiently to eat and drink independently.

At 24-h post infarction, the rats were placed under deep anesthesia with isoflurane. The rats were then sacrificed, and the hearts excised and placed in the PBS buffer. The infarct area was identified by TTC (2,3,5-triphentltetrazolium chloride) staining (illustrated in the Scheme 1B of the enclosed box inset). The risk region of myocardial tissue without TTC staining was excised and subjected to mitochondrial preparations and biochemical analysis (denoted by IR in the scheme 1B). The remaining tissue as non-ischemic region of served as the control or normal region (denoted by NR in the Scheme 1B). The ratio (w/w) of risk region tissue to non-ischemic region tissue is $37.4 \pm 11.9 \%(n=19)$.

\section{Analytical Methods}

Optical spectra were measured on a Shimadzu 2600 UV/VIS recording spectrophotometer. The protein concentrations of mitochondrial preparations were determined by the Lowry method using BSA as a standard. The concentrations of $\mathrm{Q}_{1}$ and $\mathrm{Q}_{2}$ were determined by absorbance spectra from $\mathrm{NaBH}_{4}$ reduction using a millimolar extinction coefficient of $\varepsilon_{(275 \mathrm{~nm}-290 \mathrm{~nm})}=12.25 \mathrm{mM}^{-1} \mathrm{~cm}^{-1}$. Optical spectra were measured on a Shimadzu UV2600 recording spectrophotometer. The heme $b$ and $a a_{3}$ concentrations of isolated mitochondria were calculated from the differential spectrum between dithionite reduction and ferricyanide oxidation.

Mitochondria were prepared from rat hearts by differential centrifugation as described in the published method $[6,22,25]$. Mitochondria were precipitated by centrifugation at $20,000 \times$ $\mathrm{g}$ for $10 \mathrm{~min}$ in the final step and re-suspended in media (M-buffer) containing the following agents (in mM): mannitol (230), sucrose (70), EDTA (1), Trizma (1), pH 7.4. Mitochondrial respiration (or NADH-lined OCR) was measured by the polarographic method using a Clark-type oxygen electrode (Oxytherm, Hansatech Instruments, Norfolk, England) at $30^{\circ} \mathrm{C}$ by following the same protocol as detailed in a previous publication [22]. The electron transfer activities of Complexes I-IV from the heart mitochondrial preparations were assayed by a published method [25]. The recovery of mitochondria from the post-ischemic rat heart is $24.3 \pm 2.6 \%$ for non-ischemic region ( $n=3)$, and $20.0 \pm 0.4 \%$ for risk region $(n=3)$ based on measuring percent recovery of citrate synthase activity in isolated mitochondria and tissue homogenate. The mitochondria as prepared contain $474.618 .2 \mathrm{nmol}$ heme $\mathrm{b} / \mathrm{mg}$ protein and 
$596.914 .7 \mathrm{nmol} \mathrm{aa} / \mathrm{mg}$ protein for non-ischemic region, $456.310 .9 \mathrm{nmol}$ heme $\mathrm{b} / \mathrm{mg}$ protein and $511.421 .0 \mathrm{nmol} \mathrm{aa_{3 }} / \mathrm{mg}$ protein for the infarct tissue, and no detectable contamination of the mitochondrial preparation with nuclear (probed with histone) or cytosolic proteins (probed with GAPDH).

Measurement of the mitochondrial State 3 ATP generation flux was conducted by combining oxygen electrode and ATP assay to simultaneously monitor mitochondrial state 3 ATP generation flux and OCR as reported in the literatures $[18,21]$. The mitochondrial ATP flux (accumulated ATP within $1 \mathrm{~min}$ ) was measured using ATP Bioluminescent Assay Kit (Sigma-Aldrich, St. Louis, MO) following manufacturer's protocol. The mitochondrial state 3 OCR was simultaneously measured on the Oxytherm under the conditions as previously described. Briefly, the mitochondrial preparation (to a final of $0.4 \mathrm{mg} / \mathrm{mL}$ ) was added into NADH-linked respiration buffer containing Ap5A (adenylate kinase inhibitor, $20 \mu \mathrm{M}$ ), to which ADP (to a final of $1 \mathrm{mM}$ ) was added. $5 \mu \mathrm{L}$ of reaction mixture was withdrawn from the reaction chamber and immediately added into $495 \mu \mathrm{L}$ of pre-heated ATP-assay buffer $\left(70{ }^{\circ} \mathrm{C}, 10 \mathrm{~min}\right)$ as initial ATP concentration. Another $5 \mu \mathrm{L}$ of reaction mixture was sampled 20 -sec and 40-sec after the initial sampling as the final ATP concentration. The linear OCR during the ATP sampling time span was ensured by the simultaneous Oxytherm polarography monitoring. The bioluminescent signal was recorded on the OrionL microplate luminometer (Titertek-Berthold Detection Systems GmbH, Pforzheim, Germany).

Measurements of mitochondrial ${ }^{\circ} \mathrm{O}_{2}{ }^{-}$production by EPR spin trapping were carried out on a Bruker EMX Micro spectrometer operating at $9.43 \mathrm{GHz}$ with $100 \mathrm{kHz}$ modulation frequency at room temperature [22]. The reaction mixture containing the NADH-linked respiration buffer supplemented with DTPA $(1 \mathrm{mM}) / \mathrm{DMPO}(90 \mathrm{mM})$ was mixed with a mitochondrial preparation (to a final concentration of $0.5 \mathrm{mg}$ protein $/ \mathrm{mL}$ ) at $30^{\circ} \mathrm{C}$ for $4 \mathrm{~min}$. The reaction mixture was then transferred to a $50-\mu \mathrm{L}$ capillary tube (Drummond Wiretrol, Broomall, PA), loaded into the EPR resonator (HS cavity, Bruker Instrument, Billerica, MA), equilibrated to $298^{\circ} \mathrm{K}$, and tuned within $2 \mathrm{~min}$. The scan of EPR spectra was started at exactly 6 min after the initial reaction. Parameters: center field $3360 \mathrm{G}$, sweep width $100 \mathrm{G}$, power $20 \mathrm{~mW}$, receiver gain $1 \times 10^{5}$, modulation amplitude $1 \mathrm{G}$, conversion time $40.96 \mathrm{~ms}$, time constant $163.84 \mathrm{~ms}$, number of scans: 5 . The spectral simulations were performed using the WinSim program developed at NIEHS by Duling [9].

The redox activities of mitochondria or tissue homogenates from the myocardium were measured by EPR with a redox probe of CM-H [20, 21]. The mitochondrial preparation or tissue homogenates in M-buffer were energized by glutamate and malate in the presence of $\mathrm{CM}-\mathrm{H}$, and then subjected to EPR measurement at $298^{\circ} \mathrm{K}$. The instrumental settings used for detecting the three-line spectrum of the nitroxide were: center field, $3360.3 \mathrm{G}$; sweep width, $60 \mathrm{G}$; microwave frequency, $9.43 \mathrm{GHz}$; power, $20 \mathrm{~mW}$; receiver gain, $5.02 \times 10^{3}$; modulation frequency, $100 \mathrm{kHz}$; modulation amplitude, $1 \mathrm{G}$; time constant, $163.84 \mathrm{~ms}$; conversion time, $41 \mathrm{~ms}$; sweep time, $42 \mathrm{sec}$; number of $\mathrm{X}$-scans, 1 . The parameters for the kinetic mode were: static field, $3360.3 \mathrm{G}$; receiver gain, $2 \times 10^{3}$; time constant, $2624.44 \mathrm{~ms}$; conversion time, 1,000 ms; sweep time, 300s; and number of scans, 1 . 
The enzymatic activity of aconitase in mitochondria was assayed by measuring the conversion of citrate to a-ketoglutarate in the presence of isocitrate dehydrogenase by the absorbance increase at $340 \mathrm{~nm}$ at $37^{\circ} \mathrm{C}$ as described in a previous publication [20].

The enzymatic activity of glutathione reductase (GR) was assayed by measuring GSSGmediated NADPH consumption by the absorbance decrease at $340 \mathrm{~nm}$ at $25^{\circ} \mathrm{C}$ as described in a previous publication [22].

The redox status of $\mathrm{NAD}^{+}$and $\mathrm{NADH}$ in the as-isolated mitochondria was determined by $\mathrm{NAD}^{+}$recycling with colorimetric method using $\mathrm{NAD}^{+} / \mathrm{NADH}$ Quantification Colorimetric Kits from Sigma-Aldrich (catalog number: MAK037) according to manufacture's instructions.

Direct measurements of mitochondrial $\Delta \Psi$ were carried out using the fluorescent probe of TMRM (tetramethylrhodamine methyl ester). Isolated rat heart mitochondrial suspension $(160 \mu \mathrm{g}$ protein/ml) was equilibrated with TMRM (final $2 \mu \mathrm{M})$ in respiration buffer containing potassium glutamate $(140 \mathrm{mM})$ and malate $(5 \mathrm{mM})$ at $30{ }^{\circ} \mathrm{C}$ for $10 \mathrm{~min}$, and the fluorescence was recorded by a 96-well microplate reader (excitation 528/20 nm, emission $620 / 40 \mathrm{~nm}$ ). Various effectors (final concentration: ADP $5 \mathrm{mM}$, oligomycin $4 \mu \mathrm{g} / \mathrm{mL}$, nigericin $5 \mu \mathrm{M}$, valinomycin $180 \mathrm{nM}$ ) were then injected into the specified wells, and the fluorescence was continuously monitored for additional $25 \mathrm{~min}$. Heat denatured mitochondria $\left(70{ }^{\circ} \mathrm{C}\right.$ for 10 -min), M-buffer without mitochondria, as well as trace amount of ethanol (vehicle control of compounds oligomycin, nigericin or valinomycin) were served as background controls. Most wells started in state 2 conditions (containing the energetic respiration buffer, mitochondria, and TMRM) except the state 4 control contained additional $\mathrm{ADP}$ and oligomycin in the reaction mixture at the onset of the measurement.

\section{Immunoblotting Analysis}

Western blotting with mitochondrial preparations was performed as described previously [20-22, 25]. Immunoblotting was carried out with one of: an anti-51 kDa antibody (against the FMN-binding subunit of complex I, generated in-house), an anti-75 kDa polyclonal antibody (against the $75 \mathrm{kD}$ subunit of complex I, generated in-house), an anti-ND1 (hydrophobic protein of complex I, from Santa Cruz Biotechnology, Dallas, TX), an anti-70 $\mathrm{kDa}$ antibody (against the FAD-binding subunit of complex II, generated in-house), an antiFeS antibody (monoclonal antibody against Rieske iron-sulfur protein of complex III), an anti-CoX I antibody (monoclonal antibody against the subunit 1 of complex IV, from Santa Cruz Biotechnology), or an anti-aconitase, or anti-glutathione reductase antibody (polyclonal antibodies from Santa Cruz Biotechnology).

\section{Data Analysis}

Statistical analysis was performed using Origin 9.1 data analysis software. Results were presented as mean \pm SEM, followed by group number $(n)$, and $p$ value. Comparisons between two groups (the data sets of Figs. 1, 2B, 3, 4B, 5, 6, 8C-8D, and 9) were assessed by Student's $t$-test. Comparisons among multiple groups (the data set of three groups in Fig. 5 ) were assessed by one-way ANOVA followed by Tukey's post hoc tests. A probability value of $p<0.05$ was used to establish statistical significance. 


\section{RESULTS}

\section{Study design}

Overall rationale and experimental design to assess states 2-4 OCR and the effect of $\Delta \mathrm{pH}$ and $\Delta \Psi$ on the mitochondria-mediated ${ }^{\circ} \mathrm{O}_{2}{ }^{-}$generation are illustrated in the Scheme $1 \mathrm{C}$.

\section{State 3 and state 4 OCR in the post-ischemic heart}

It has been hypothesized that overproduction of oxygen free radicals during myocardial IR can depolarize mitochondrial membrane potentials and uncouple mitochondrial respiration $[8,10]$. As indicated in Fig. 1A and 1B, NADH-linked and ADP-stimulated respiration of the mitochondria from the post-ischemic myocardium was significantly decreased. The ADP-independent OCR (state 4) was further deceased. The FCCP-induced uncoupled respiration was decreased, and the respiratory control index (the ratio of state 3 to state 4) was also decreased as indicated in Fig. 1C.

To evaluate the effect of IR on the efficacy of oxidative phosphorylation, we determined mitochondria-mediated ATP generation flux under the state 3 OCR in the presence of a higher ADP concentration $(1 \mathrm{mM})$. The ATP production flux mediated by isolated mitochondria of the risk region was significantly diminished (Fig. 1D).

\section{$\cdot \mathrm{O}_{2}$ - generation mediated by the mitochondria of the non-ischemic myocardium}

The NADH-linked ${ }^{\circ} \mathrm{O}_{2}{ }^{-}$production mediated by normal mitochondria at different respiratory states was induced by glutamate/malate (NADH-linked), and measured by EPR spin-trapping with DMPO. A SOD 1 ( $\mathrm{Zn}-\mathrm{Cu}$ superoxide dismutase)-sensitive four-line spectrum of DMPO/ $/^{\circ} \mathrm{OH}$ adduct was detected, indicating that ${ }^{\circ} \mathrm{O}_{2}{ }^{-}$generation was mediated by the normal mitochondria under state 2 conditions (Fig. 2A, b). Addition of ADP (state 3 respiration) significantly diminished mitochondria-mediated ${ }^{\circ} \mathrm{O}_{2}{ }^{-}$generation by $59.6 \pm 7.7 \%$, indicating that coupling of enhanced $\mathrm{O}_{2}$ consumption with oxidative phosphorylation for ATP synthesis decreased the $\mathrm{e}^{-}$leakage to molecular oxygen (Fig. 2A, $c$; and Fig. 2B). In the presence of oligomycin (state 4 respiration), mitochondria-mediated ${ }^{\circ} \mathrm{O}_{2}{ }^{-}$generation induced by glutamate/malate was restored to the level of state 2 respiration (Fig. 2A, $d$; and Fig. 2B). However, the addition of FCCP $(1 \mu \mathrm{M})$ to uncouple the $\Delta \Psi$ and $\Delta \mathrm{pH}$ significantly decreased the ${ }^{\bullet} \mathrm{O}_{2}{ }^{-}$production to the level of state 3 conditions (Fig. 2A, e; and Fig. 2B).

\section{$\cdot \mathrm{O}_{2}-$ generation mediated by the mitochondria of the post-ischemic heart}

The measured NADH-linked ${ }^{\circ} \mathrm{O}_{2}{ }^{-}$production by mitochondria isolated from the postischemic myocardium was enhanced by $143.4 \pm 33.1 \%$ under state 3 conditions (Fig. 2B). In the absence of ADP (state 2 in Fig. 2B) or in the presence of oligomycin (state 4 in Fig. 2B), the ${ }^{\bullet} \mathrm{O}_{2}{ }^{-}$generation mediated by post-ischemic mitochondria was not significantly different from the level produced by the state 3 conditions, suggesting that ${ }^{\circ} \mathrm{O}_{2}{ }^{-}$generation by the post-ischemic mitochondria was less dependent on $\Delta \mathrm{pH}$. There was no significant difference in the ${ }^{\circ} \mathrm{O}_{2}{ }^{-}$production by the post-ischemic mitochondria and normal mitochondria under the oligomycin-induced state 4 conditions and the FCCP-induced uncoupling conditions (Fig. 2B). 


\section{Mitochondrial ETC and aconitase activities in the post-ischemic myocardium}

Mitochondria were then subjected to analysis of ETC enzymatic activities. As indicated in Fig. 3A, a significant decrease in ETC activities was detected in the post-ischemic mitochondria compared to control, including complex I, complex II, complex III, and complex IV. The defect in the ETC activities was well correlated with the impairment of ADP-stimulated and FCCP-stimulated OCRs (Figs. 1A-1B and Fig. 3A).

We used the redox sensor aconitase as another index of increased free radical production in IR mitochondria [12-14, 37]. A severe decline in the enzymatic activity of aconitase to $57.5 \pm 6.6 \%$ in the mitochondria of the risk region (Fig. 3B) was detected, which was corroborated by increased mitochondrial ${ }^{\circ} \mathrm{O}_{2}^{-}$production in the post-ischemic myocardium. There was a modest decrease in protein expression of aconitase in the mitochondria of the post-ischemic myocardium (Fig. 3B).

\section{NAD+ and NADH in the mitochondria of post-ischemic rat heart}

The amount of $\mathrm{NAD}^{+}$in the isolated mitochondria was decreased from $3.44 \pm 0.06$ (in $\mathrm{nmol} / \mathrm{mg}$ protein $)$ in the non-ischemic region to $1.42 \pm 0.05$ in the risk region $(p<0.001, n=$ $9)$ under non-energized conditions, indicating a depletion of $\mathrm{NAD}^{+}$and $\mathrm{NADH}$ pool after myocardial I/R. However, the ratio of $\left[\mathrm{NAD}^{+}\right] /[\mathrm{NADH}]$ under energized conditions in the presence of glutamate plus malate was increased from $2.91 \pm 0.08$ in normal mitochondria to $8.12 \pm 0.37$ in post-ischemic mitochondria $(p<0.001, n=8)$, implicating IR predisposed the mitochondria more oxidized physiological setting.

\section{Mediation of uncoupling mitochondrial $\Delta \mathrm{pH}$ and $\Delta \Psi$ in the myocardium and HL-1 myocytes by nigericin, valinomycin, and gramicidine}

To gain insights into the role of the electrochemical gradient in the post-ischemic injury, the specific inhibitors of $\Delta \mathrm{pH}$ and $\Delta \Psi$ were used, including nigericin, valinomycin, and gramicidine. The nature of their function as uncouplers was evaluated in the model system of isolated mitochondria with polarographic analysis, and in the HL-1 myocytes using the technique of extracellular flux analyzer.

Nigericin functions as an antiporter of $\mathrm{H}^{+}$and $\mathrm{K}^{+}$; and thus, dissipates the $\Delta \mathrm{pH}$ and increases the $\Delta \Psi$ via enhancing the $\mathrm{K}^{+}$gradient across the inner membrane. Nigericin consistently partially uncoupled the normal mitochondria in the absence of ADP (Fig. 4A), suggesting that the proton backpressure of $\Delta \mathrm{pH}$ negatively mediates electron transport for the OCR of mitochondria. The nature of nigericin functioning as an uncoupler was further evaluated in the model system of myocyte (HL-1 cell line). As indicated in Fig. 4B, nigericin partially uncoupled the OCR in HL-1, which resulted in a lower reserve bioenergetic capacity ( $50 \%)$ compared with that of FCCP-induced uncoupling of the OCR in HL-1.

Valinomycin is a potassium-specific transporter and facilitates the movement of $\mathrm{K}^{+}$across the membrane down an electrochemical potential gradient, leading to uncoupling oxidative phosphorylation in biological systems. Valinomycin partially uncoupled the normal mitochondria (Fig. 4A), indicating that the $\Delta \psi$ also negatively mediates electron transport 
for the OCR. However, it was observed that valinomycin completely uncoupled the OCR of HL-1 myocytes, exhibiting an uncoupling efficiency similar to that of FCCP (Fig. 4B).

Gramicidin partially uncoupled the OCR of normal mitochondria (Fig. 4A) via dissipating $\Delta \Psi$. In agreement with this result, gramicidin partially uncoupled the OCR of HL-1 myocytes as determined by extracellular flux analysis (Fig. 4B).

\section{The effect of nigericin on NADH-linked ${ }^{\circ} \mathrm{O}_{2}$ - production by the mitochondria of the post- ischemic myocardium}

Nigericin abolished normal mitochondria-mediated ${ }^{\circ} \mathrm{O}_{2}{ }^{-}$generation under state 2 (Fig. 5A) and oligomycin-induced state 4 conditions respectively (Fig. 5B). However, the quenching effect of nigericin on $\mathrm{NADH}$-linked ${ }^{\circ} \mathrm{O}_{2}{ }^{-}$generation was less pronounced in the mitochondria isolated from the risk region (Fig. 5A and Fig. 5B).

\section{The effect of valinomycin on $\mathrm{NADH}-$-linked ${ }^{\circ} \mathrm{O}_{2}{ }^{-}$production by the mitochondria of the post- ischemic heart}

Valinomycin reduced ${ }^{\circ} \mathrm{O}_{2}{ }^{-}$generation by normal mitochondria under state 2 (Fig. 5A) and state 4 conditions (Fig. 5B). However, the quenching effect of valinimycin was less distinct in the post-ischemic mitochondria. The addition of valinomycin only modestly decreased NADH-linked ${ }^{\circ} \mathrm{O}_{2}{ }^{-}$generation under state 2 (Fig. 5A) and state 4 conditions (Fig. 5B).

\section{Effect on the $\mathrm{H}_{2} \mathrm{O}_{2}$ emission by the mitochondria of the 24-h post-ischemic heart}

The emission of NADH-linked $\mathrm{H}_{2} \mathrm{O}_{2}$ mediated by normal mitochondria and post-ischemic mitochondria was measured using Amplex Red/HRP according to previously published approach [4-5, 21]. The levels of $\mathrm{H}_{2} \mathrm{O}_{2}$ emitted from normal and post-ischemic mitochondria were significantly higher in the state 4 conditions, and lower in the state 3 and FCCP-uncoupling conditions ( $n=8$, comparison of three groups in Fig. 6A), supporting the proton backpressure and membrane potential from electrochemical gradient as the endogenous source ROS. The amount of $\mathrm{H}_{2} \mathrm{O}_{2}$ emission by the post-ischemic mitochondria was significantly increased under state 3 and FCCP-uncoupling conditions (Fig. 6A), and more resistant to the quenching effect of nigericin (in Fig. 6B) and valinomycin (in Fig. 6C) as seen in the results of ${ }^{\circ} \mathrm{O}_{2}{ }^{-}$generation determined by EPR (Fig. 5). However, the capacity of a combination of nigericin and valinomycin to lower $\mathrm{H}_{2} \mathrm{O}_{2}$ emission by IR mitochondria is close to the effect of FCCP, and marginally higher than that of the single uncoupler used (data not shown).

\section{Measurements of $\Delta \psi$ and $\Delta \mathrm{pH}$ with the fluorescence probe of TMRM in the mitochondria of 24-h post-ischemic heart}

TMRM is a commonly used fluorescent dye to monitor the mitochondrial $\Delta \psi$. The lipophilic cationic probe is accumulated into the negatively charged mitochondrial matrix side by the polarized $\Delta \psi$. The fluorescence of TMRM exhibits a red shift and the fluorescent intensity is quenched when the probe is accumulated by mitochondria [36]. The higher $\Delta \psi$ derived from polarized mitochondria would yield lower fluorescent intensity, and depolarized mitochondria would give higher fluorescent intensity. 
As shown in Fig. 7A, the effect of ADP on normal mitochondria was highlighted. The ADP addition converted state 2 to state 3 conditions, and the fluorescent signals increased, confirming a shifting toward low $\Delta \psi$ status. When ATP was accumulated and ADP was exhausted over this time, the $\Delta \psi$ was gradually restored and the fluorescence returned to quenching state. The addition of oligomycin to normal mitochondria induced a transition to state 4 conditions as depicted in the Fig. 7B, the fluorescence intensity gradually decreased over the course of $10-\mathrm{min}$ (from $11^{\text {th }}$ to $21^{\text {st }} \mathrm{min}$ ), indicating the accumulation of $\Delta \psi$ resulted from buildup of the $\Delta \mathrm{pH}$. In contrast, ADP-stimulated fluorescent enhancement and oligomycin-induced quenching were subtle in the post-ischemic mitochondria, confirming a more depolarized status.

The effects of nigericin and oligomycin on the $\Delta \psi$ of normal mitochondria were highlighted in Figs. 7C and 7D. The addition of nigericin to normal mitochondria under state 4 conditions induced hyperpolarization as indicated by a rapid quenching of fluorescent intensity (time course of 10-15 min in Fig. 7C), confirming the nature of nigericin as the antiporter in dissipating the $\Delta \mathrm{pH}$ and enlarging the $\Delta \psi$. The addition of valinomycin to normal mitochondria in the presence of $\mathrm{K}^{+}$significantly enhanced fluorescent intensity, thus indicating abolishment of mitochondrial $\Delta \psi$ (Fig. 7D). However, the post-ischemic mitochondria were much less sensitive to the quenching effect of nigericin and the enhancing effect of valinomycin (Figs. 7C and 7D).

\section{Redox status in the mitochondria of the post-ischemic heart and the effect of nigericin}

$\mathrm{X}$-band EPR was employed to analyze the redox status of normal and post-ischemic mitochondria during the oxidation of $\mathrm{CM}-\mathrm{H}$ to a stable nitroxide. It was observed that postischemic mitochondria exhibited a higher redox activity in mediating CM-H oxidation than normal mitochondria under basal or non-energized conditions $(4.53 \pm 0.30 \mathrm{nmol} / \mathrm{min} / \mathrm{mg}$ protein vs $3.63 \pm 0.02 \mathrm{nmol} / \mathrm{min} / \mathrm{mg}$ protein, $n=4$ and $p<0.05$ ).

Under the NADH-linked energized and oligomycin-induced state 4 conditions, the redox activity of post-ischemic mitochondria was significantly increased (Fig. 8A and Fig. 8B), supporting the conclusion of a more oxidized physiological setting in the post-ischemic myocardium. Nigericin treatment significantly enhanced the redox activity of normal mitochondria to the level of post-ischemic mitochondria, but did not impact the redox activity of post-ischemic mitochondria to a significant level (Fig. 8C), indicating that impairment of $\Delta \mathrm{pH}$ predisposed the post-ischemic myocardium to a more oxidized redox status. The above results were further evaluated and confirmed using tissue homogenates containing mitochondria and cytosol. As indicated in Fig. 8D, the redox activity of tissue homogenate from the post-ischemic myocardium was also significantly higher. Treatment of the non-ischemic tissue homogenates with nigericin enhanced their redox activity to the level of the post-ischemic tissue homogenates, whereas nigericin treatment did not significantly alter the redox activity of the tissue homogenates from the risk region.

\section{The effect of nigericin on the redox status of mitochondria with SOD2 overexpression}

To understand if the ${ }^{\circ} \mathrm{O}_{2}{ }^{-}$production by the mitochondria contributed to enhanced redox activity induced by nigericin or uncoupling $\Delta \mathrm{pH}$, the mouse model of SOD2-tg was 
employed. The mitochondria isolated from SOD2-tg exhibited no detectable NADHlinked ${ }^{\circ} \mathrm{O}_{2}{ }^{-}$generation and a higher $\mathrm{NADH}$-linked $\mathrm{H}_{2} \mathrm{O}_{2}$ production under energized conditions [21]. The mouse model of SOD2-tg was thus an ideal system to evaluate whether or not mitochondrial ${ }^{\circ} \mathrm{O}_{2}^{-}$generation can have an impact on enhanced redox activity mediated by uncoupling $\Delta \mathrm{pH}$ (Figs. 8A-8C). Under state 2 and energized conditions, we found that the mitochondria from SOD2-tg murine hearts displayed a lower redox activity, which is consistent with the conclusion of a more reductive physiological setting in the myocardium of SOD2-tg mice [21]. Nigericin treatment significantly enhanced the redox activities of mitochondria from both wild type and SOD2-tg mice. However, there was no statistically significant difference in nigericin-induced redox activity enhancement between wild type and SOD2-tg mitochondria, supporting the conclusion that uncoupling of $\Delta \mathrm{pH}$ predisposes mitochondria to a more oxidized physiological setting, independent of ${ }^{\bullet} \mathrm{O}_{2}{ }^{-}$ generation.

\section{Mitochondrial respiration, $\Delta \mathrm{pH}$, and $\Delta \psi$ in the $3 \mathrm{~h}$ post-ischemic rat heart}

Multiple studies have shown substantial remodeling of mitochondria over the first $24 \mathrm{~h}$ of reperfusion, including fusion, fission, mitophagy, the inner membrane, and ETC itself. Additional studies were thus conducted in the model of rat heart subjected to $30 \mathrm{~min}$ of coronary ligation and an earlier time point of $3 \mathrm{~h}$ reperfusion in vivo. Similar respiratory impairments in the state 3 OCR, FCCP-induced uncoupling OCR, and respiratory control index, were detected in the $3 \mathrm{~h}$ post-ischemic mitochondria (Supplementary Figure 1). We have further detected an enhanced $\mathrm{NADH}-$ linked ${ }^{\circ} \mathrm{O}_{2}{ }^{-}$generation at state 3 conditions as well as a less quenching effect of nigericin on the state $2^{\circ} \mathrm{O}_{2}{ }^{-}$generation by the $3 \mathrm{~h}$ postischemic mitochondria as seen in the $24 \mathrm{~h}$ post-ischemic mitochondria (Supplementary Figure 1). However, the quenching effect of valinimycin on the state $2^{\circ} \mathrm{O}_{2}{ }^{-}$generation in the $3 \mathrm{~h}$ post-ischemic mitochondria observed was more significant, suggesting a portion of $\Delta \psi$ was conserved in early point of reperfusion, which contributes to a moderately enhanced state $2{ }^{\circ} \mathrm{O}_{2}{ }^{-}$generation in part (Supplementary Figure 1).

\section{DISCUSSION}

The main findings of this study elucidated (I) IR-induced $\Delta \mathrm{pH}$ impairment prompted the post-ischemic myocardium to a more oxidized redox setting, which appears to be associated with enhanced uncoupled respiration, and (2) IR-induced impairment of both $\Delta \mathrm{pH}$ and $\Delta \Psi$ increased state 3 mitochondrial ${ }^{\circ} \mathrm{O}_{2}{ }^{-}$generation.

\section{Uncoupled respiration in the post-ischemic heart}

Current studies confirmed that the coupling of $\mathrm{O}_{2}$ consumption with ATP synthesis was impaired after in vivo myocardial ischemia and reperfusion injury, supporting a significant defect in respiration uncoupled in the post-ischemic myocardium. Current studies also supported the concept that mitochondrial dysfunction occurring in post-ischemic injury is caused by overproduction of mitochondria-derived oxygen free radicals (Fig. 1A-1B vs Fig. 2B under state 3 conditions). The results were in agreement with those studied by the Langendorff-perfused rat heart $[6,25]$. These results further support the concept that increasing electrochemical gradients and proton backpressure drive a portion of the $\mathrm{e}^{-}$ 
leakage for ${ }^{\circ} \mathrm{O}_{2}{ }^{-}$production under normal physiological conditions. Post-ischemic injury damaged the ETC activities, and uncoupled the $\Delta \mathrm{pH}$ across the inner membrane of the postischemic mitochondria. The $\Delta \Psi$, secondary to $\Delta \mathrm{pH}$, was the source of ${ }^{\bullet} \mathrm{O}_{2}{ }^{-}$generation under normal physiological conditions, and uncoupled in the mitochondria of the post-ischemic heart. Together the results from nigericin and valinomycin, it was concluded that neither $\Delta \mathrm{pH}$ nor $\Delta \Psi$ significantly contributes to ${ }^{\circ} \mathrm{O}_{2}{ }^{-}$generation by the mitochondria of 24 -h postischemic heart.

It's worth noting that the mitochondria studied are predominately at 24-h reperfusion. Substantial impairment of ETC activity and oxidative phosphorylation and most important here, of damage of inner membrane persists at this intermediate time of reperfusion. Therefore, mitochondrial remodeling has not resulted in tissue mitochondria with normal function.

It appears that direct damage to the ETC accounts for a significant component of the respiratory defect and increased ROS production in the post-ischemic myocardium of current study. However, the inner membrane damage during myocardial IR has been shown to involve significant damage or depletion of cardiolipin [26-28, 30-32]. Cardiolipin of the inner membrane is postulated serving as the electrical "insulator" basis for the physiology of $\Delta \mathrm{pH}$ and $\Delta \Psi$. IR-induced cardiolipin oxidation or cardiolipin depletion can further contribute to impairment of $\Delta \mathrm{pH}$ and $\Delta \Psi$.

\section{$\triangle \mathrm{pH}$ in the post-ischemic heart}

As indicated by EPR spin-trapping analysis, nigericin treatment decreased NADHlinked ${ }^{\circ} \mathrm{O}_{2}{ }^{-}$generation in normal mitochondria (at state 2 and state 4 conditions in Figs. 5A and $5 \mathrm{~B}$ ), supporting the conclusion that $\Delta \mathrm{pH}$ is a source of ${ }^{\circ} \mathrm{O}_{2}{ }^{-}$production under normal physiological conditions. The result was basically consistent with early studies with reverse electron flow-induced ROS through complex I [24]. Because the $\Delta \mathrm{pH}$ of the mitochondrial inner membrane was high under conditions of low ADP (state 2) or inhibition of ATP synthase, external addition of ADP thus induced state 3 respiration by increased proton influx through the proton channel of ATP synthase, diminishing $\Delta \mathrm{pH}$ and increasing ATP synthesis. The proton pumps of the ETC then responded with increased proton pumping and electron flow to maintain the electrochemical gradient, leading to the consequence of increasing $\mathrm{O}_{2}$ consumption (Fig. $1 \mathrm{~A}$ and $1 \mathrm{C}$ ). We have detected that the addition of ADP (state 3 conditions) significantly decreased ${ }^{\circ} \mathrm{O}_{2}{ }^{-}$production mediated by normal mitochondria (in Fig. 2) from the models of rat and mouse hearts [20, 22], further reinforcing the above conclusion.

In the post-ischemic myocardium, we have hypothesized that ischemia and reperfusion injury can mediate $\Delta \mathrm{pH}$ impairment. The hypothesis was largely supported by the results of current studies such as an IR-mediated decreased state 3 OCR ex vivo (Fig. 1A and 1C), and in the Langendorff-perfused rat heart $[6,25]$. The addition of ADP failed to reduce the ${ }^{\circ} \mathrm{O}_{2}{ }^{-}$ production mediated by the mitochondria of the post-ischemic myocardium (Fig 2). The result was corroborated by the respiratory analysis showing that post-ischemic mitochondria exhibited impaired OCRs for both ADP-enhanced (Fig. 1A and 1C) and nigericin-enhanced conditions (data not shown). Furthermore, the nigericin-mediated quenching effect of ${ }^{\circ} \mathrm{O}_{2}{ }^{-}$ 
production was much less pronounced in the mitochondria of the post-ischemic myocardium due to the defect in $\Delta \mathrm{pH}$ (Fig. 5A vs Fig. 5B). The results generally supported that a decrease in $\Delta \mathrm{pH}$ is correlated with decreasing ${ }^{\circ} \mathrm{O}_{2}{ }^{-}$generation by the mitochondria as predicted in previous report [7].

As the electrons pass through each complex of the ETC, there is an energy drop in reduction potential that provides the driving force required for proton pumping. Energy stored in the $\Delta \mathrm{pH}$ and $\Delta \psi$ is the potential energy driving protons to return to the matrix for ATP synthesis. Therefore, damage of the ETC activity by the post-ischemic injury was likely directly involved in impaired proton pumping and $\Delta \mathrm{pH}$ impairment, which has been reported in the complex I and complex IV of mouse model [42] as well as the complex I and complex III of rat model $[3,6,25]$.

Our recent progress has indicated increased irreversible cysteine sulfonation in the complex I and complex III to be partially responsible for oxidative impairment of ETC in the postischemic heart. Specifically, several specific sites of irreversible cysteine S-sulfonation in the complex I of post-ischemic heart are involved in the ligands of iron-sulfur clusters, which controls its electron transport activity ${ }^{1}$. Likely, IR-induced irreversible cysteine oxidation of ETC may directly or indirectly contributes to $\Delta \mathrm{pH}$ impairment. Increased complex I Sglutathionylation has been detected in the post-ischemic heart [3]. It may not necessarily contribute to $\Delta \mathrm{pH}$ impairment because reversal of glutathionylation by dithiothreitol (DTT) did not restore complex I activity [19].

\section{$\Delta \Psi$ in the post-ischemic heart}

EPR analysis clearly revealed that valinomycin significantly diminished $\mathrm{NADH}$-linked ${ }^{\circ} \mathrm{O}_{2}{ }^{-}$ generation mediated by the isolated normal mitochondria, supporting mitochondrial membrane potential as one of components to regulate electron leakage for ${ }^{\circ} \mathrm{O}_{2}{ }^{-}$production under normal physiological conditions. The result was supported by early published work using vesicle-reconstituted complex III [34, 40]. Ischemia and reperfusion injury obviously impaired $\Delta \Psi$ and subsequently disrupted the above regulation since ${ }^{\circ} \mathrm{O}_{2}{ }^{-}$production by the isolated post-ischemic mitochondria was less sensitive to the valinomycin treatment (Fig. 5A vs Fig. 5B). This conclusion was upheld by respiratory analysis, which indicated that postischemic mitochondria displayed a declined FCCP-mediated (Fig. 1A and 1B) and valinomycin-induced uncoupling of OCRs (data not shown). Similar results have documented that reverse electron flow-induced ROS production can be mediated by the $\Delta \Psi$ of the mouse heart [33] and brain mitochondria [38], but decreased due to the depolarized $\Delta \Psi$ caused by ischemia of the mouse heart [33].

\section{Redox dysfunction in the post-ischemic heart}

The above results were further supported by the redox assays using the spin probe $\mathrm{CM}-\mathrm{H}$. In normal mitochondria, the $\Delta \mathrm{pH}$ and $\Delta \Psi$ build up when $\Delta \mathrm{pH}$ is not being used for ATP synthesis. This "proton backpressure" derived from the $\Delta \mathrm{pH}$ and $\Delta \Psi$ can control and restrict

${ }_{1}^{1}$ Kang PT, Chen CL, Lin P, Zhang L, Chen YR (2017) FASEB J April 2017 31:680.1. http://www.fasebj.org/content/ 31/1_Supplement/680.1.abstract 
electron transport and the OCR, predisposing the normal mitochondria to a more reduced physiological setting. Uncoupling of mitochondrial $\Delta \mathrm{pH}$ and $\Delta \Psi$ by nigericin (Fig. 4A) or FCCP (Fig. 1A and 4A) appreciably enhances the electron transfer and OCRs, prompting the redox status of mitochondria to become more oxidized. This hypothesis was substantiated by the results in which nigericin or FCCP was found to mediate enhancement of mitochondrial redox activity in converting CM-H to its stable nitroxide (Fig. 8).

We have further found that valinomycin treatment failed to enhance the redox activity of normal mitochondria under energetic conditions despite increasing the uncoupled OCR (Fig. 4A-4B and Fig. 8). It is likely that dissipation of the $\Delta \Psi$ did not significantly promote the normal mitochondria to a more oxidized redox status. However, nigericin treatment of normal mitochondria increased its redox activity to the level of the mitochondria isolated from the risk region (Fig. $8 \mathrm{~A}-8 \mathrm{~B}$ ), suggesting $\Delta \mathrm{pH}$ as the major component in regulating the redox status of the mitochondria and myocardium (Fig. 6C), and impairment of $\Delta \mathrm{pH}$ as one of the key factors in predisposing the post-ischemic myocardium to a more oxidized physiological setting.

In post-ischemic mitochondria, treatment with nigericin (Fig. 8) or FCCP (data not shown) exerted no significant impact on the redox activity of post-ischemic mitochondria or the post-ischemic myocardium, further confirming IR-mediated injury of the electrochemical gradient and the consequence of redox dysfunction caused by IR injury. Therefore, impairment of $\Delta \mathrm{pH}$ and $\Delta \Psi$ weakened the ability of the membrane instinct to restore "proton backpressure" under state 2 or state 4 conditions, provoking the more oxidized postischemic mitochondrial redox status.

There are other factors associated with the redox dysfunction during myocardial ischemia and reperfusion. These factors can include overproduction of ${ }^{\circ} \mathrm{O}_{2}{ }^{-}$and other ROS, which would increase the prooxidant activity of aconitase via producing hydroxyl radical by Fenton reaction and inactivating the [4Fe-4S] cluster (Fig. 3B) [37]. Aconitase in mitochondria was thus a redox sensor of ${ }^{\bullet} \mathrm{O}_{2}^{-}\left(\mathrm{k} \sim 10^{7} \mathrm{M}^{-1} \mathrm{~s}^{-1}\right.$ for the reaction of aconitase with ${ }^{\bullet} \mathrm{O}_{2}^{-}$), and impairment of aconitase activity was thus correlated with redox dysfunction in the post-ischemic heart.

However, the results of evaluating the SOD2-tg mouse model has concluded that ${ }^{\circ} \mathrm{O}_{2}{ }^{-}$ production may not necessarily correlate to a more oxidized redox status driven by $\Delta \mathrm{pH}$ uncoupling, indicating the strength of SOD2-tg. As reported previously enhanced NADHlinked $\mathrm{H}_{2} \mathrm{O}_{2}$ generation as well as modest catalase upregulation were detected in the mitochondria of SOD2-tg heart [21]. It should not be ruled out that excess downstream $\mathrm{H}_{2} \mathrm{O}_{2}$ may exert a noticeable effect to increase redox activity of nigericin-treated SOD2-tg mitochondria. Investigation using the mouse model of mitochondrial catalase overexpression may compensate for the above weakness.

Post-ischemic injury of antioxidant enzymes associated with the mitochondrial GSH pool further contributed to the redox dysfunction of post-ischemic mitochondria, but might not necessarily enhance the redox activity of CM-H oxidation by the post-ischemic mitochondria. We further observed a defect in glutathione reductase (GR2) in enzymatic 
activity (a reduction of $69.5 \pm 6.7 \%, n=6$ ) and protein expression (a reduction of $60.3 \pm 14.5 \%, n=3$ ) in the mitochondria of the post-ischemic myocardium (Supplementary Figure 2A and 2C), which was correlated with the higher GSSG/GSH ratio and enhanced protein S-glutathionylation reported previously [3]. However, post-ischemic injury of the total glutathione reductase in the tissue homogenate was not as significant as the GR2 impairment detected in the post-ischemic mitochondria (Supplementary Figure 2B), reinforcing the critical role of mitochondrial dysfunction in the redox dysfunction of the post-ischemic myocardium.

A marginal decrease by $28.4 \pm 8.6 \%(p<0.05, n=6)$ in the glutathione peroxidase (GPx2) activity in the post-ischemic mitochondria was further detected, supporting a decreased ability to scavenge $\mathrm{H}_{2} \mathrm{O}_{2}$, increased oxidant stress, and interrupted redox balance in mitochondria. In the tissue homogenate of the post-ischemic myocardium, we detected a similar decline in GPx activity, indicating no differential impairment between mitochondria and the cytosol during myocardial IR.

\section{Relevance of cardioprotection}

It has been well documented that mitochondria are a target of cardioprotection induced by humoral factors released during remote ischemic preconditioning [15], preconditioning effect of TNFa [23], and postconditioning activation of mitochondrial STAT3 [17]. However, the in-depth mechanism of cardioprotection remains to be elucidated. Current studies may provide insights into potential mechanisms involved in protecting $\Delta \mathrm{pH}$ from dissipation, maintaining membrane potential, and stabilizing the redox status to preserve mitochondrial function and reduce infarction.

\section{CONCLUSION}

The present studies provide insights regarding the mechanisms of $\Delta \mathrm{pH}$ and $\Delta \Psi$ in controlling ${ }^{\bullet} \mathrm{O}_{2}{ }^{-}$generation by mitochondria under conditions of normal physiology and myocardial infarction. As delineated in the Fig. 10, the underlying mechanism has been characterized by impaired $\mathrm{pH}$ gradient and membrane potential, which enhance ${ }^{\circ} \mathrm{O}_{2}{ }^{-}$ generation from ETC in the presence of ADP (state 3 conditions), and promote the postischemic mitochondria and myocardium to a more oxidized redox setting. Treatment with nigericin and valinomycin exerts a more pronounced effect on $\Delta \mathrm{pH}-$ and $\Delta \Psi-$ mediated ${ }^{\circ} \mathrm{O}_{2}{ }^{-}$generation by the normal mitochondria than by the post-ischemic mitochondria. Disruption of the $\Delta \mathrm{pH}$ with nigericin predisposes the normal mitochondria to a more oxidized physiological setting as seen in the redox status of the post-ischemic mitochondria and myocardium. The mechanism addressed here provides a useful concept for understanding the mechanism of post-ischemic injury involved in $\Delta \mathrm{pH}$ and $\Delta \Psi$. Recognition of this mechanism is valuable in understanding the fundamental basis of mitochondrial biology in the disease of myocardial infarction.

\section{Supplementary Material}

Refer to Web version on PubMed Central for supplementary material. 


\section{Acknowledgments}

This work was supported by National Institutes of Health Grant HL83237 (to Y.-R C), and HL115114 (to WMC).

\section{Abbreviations}

$\begin{array}{ll}\text { IR } & \text { myocardial ischemia and reperfusion } \\ \Delta p & \text { electrochemical gradient } \\ \Delta \mathbf{p H} & \text { mH gradient or proton gradient } \\ \Delta \Psi & \text { superoxide anion radical } \\ \mathbf{O}_{2}^{-} & \text {electron paramagnetic resonance } \\ \text { EPR } & \text { oxygen consumption rate } \\ \text { OCR } & \text { electron transport chain } \\ \text { ETC } & \text { electron transfer activity } \\ \text { ETA } & \text { reactive oxygen species } \\ \text { ROS } & \text { respiratory control ratio } \\ \text { RCR } & \end{array}$

TMRM

tetramethylrhodamine methyl ester CM-H, 1-Hydroxy-3methoxycarbonyl-2,2,5,5-tetramethylpyrrolidine

FCCP carbonyl cyanide-4(trifluoromethoxy)phenylhydrazone

complex I

(NADH-ubiquinone reductase)

complex II

(succinate-ubiquinone reductase)

complex III

(ubiquinol-cytochrome $c$ reductase)

complex IV

(cytochrome $c$ oxidase)

DCPIP

dichlorophenyl indophenol

GAPDH

glyceraldehyde-3-phosphate dehydrogenase

DMPO

5,5-dimethyl-1-pyrroline $N$-oxide

\section{References}

1. Ambrosio G, Zweier JL, Duilio C, Kuppusamy P, Santoro G, Elia PP, Tritto I, Cirillo P, Condorelli M, Chiariello M, et al. Evidence that mitochondrial respiration is a source of potentially toxic oxygen free radicals in intact rabbit hearts subjected to ischemia and reflow. J Biol Chem. 1993; 268:18532-18541. [PubMed: 8395507]

2. Chen CL, Chen J, Rawale S, Varadharaj S, Kaumaya PP, Zweier JL, Chen YR. Protein tyrosine nitration of the flavin subunit is associated with oxidative modification of mitochondrial complex II in the post-ischemic myocardium. J Biol Chem. 2008; 283:27991-28003. [PubMed: 18682392] 
3. Chen J, Chen CL, Rawale S, Chen CA, Zweier JL, Kaumaya PT, Chen YR. Peptide-based antibodies against glutathione-binding domains suppress superoxide production mediated by mitochondrial complex I. J Biol Chem. 2010; 285:3168-3180. [PubMed: 19940158]

4. Chen Q, Moghaddas S, Hoppel CL, Lesnefsky EJ. Ischemic defects in the electron transport chain increase the production of reactive oxygen species from isolated rat heart mitochondria. Am J Physiol Cell Physiol. 2008; 294:C460-466. [PubMed: 18077608]

5. Chen Q, Vazquez EJ, Moghaddas S, Hoppel CL, Lesnefsky EJ. Production of reactive oxygen species by mitochondria: central role of complex III. J Biol Chem. 2003; 278:36027-36031. [PubMed: 12840017]

6. Chen YR, Chen CL, Pfeiffer DR, Zweier JL. Mitochondrial complex II in the post-ischemic heart: oxidative injury and the role of protein S-glutathionylation. J Biol Chem. 2007; 282:32640-32654. [PubMed: 17848555]

7. Chen YR, Zweier JL. Cardiac mitochondria and reactive oxygen species generation. Circulation research. 2014; 114:524-537. [PubMed: 24481843]

8. Doliba NM, Doliba NM, Chang Q, Babsky AM, Wroblewski K, Natelson BH, Osbakken MD. Mitochondrial oxidative phosphorylation in heart from stressed cardiomyopathic hamsters. Journal of molecular and cellular cardiology. 1999; 31:543-553. [PubMed: 10198186]

9. Duling DR. Simulation of multiple isotropic spin-trap EPR spectra. J Magn Reson B. 1994; 104:105-110. [PubMed: 8049862]

10. Ferrari R. The role of mitochondria in ischemic heart disease. J Cardiovasc Pharmacol. 1996; (28 Suppl 1):S1-10.

11. Ferrari R, Ceconi C, Curello S, Cargnoni A, Pasini E, De Giuli F, Albertini A. Role of oxygen free radicals in ischemic and reperfused myocardium. Am J Clin Nutr. 1991; 53:215S-222S. [PubMed: 1845919]

12. Gardner PR, Fridovich I. Superoxide sensitivity of the Escherichia coli aconitase. J Biol Chem. 1991; 266:19328-19333. [PubMed: 1655783]

13. Gardner PR, Fridovich I. Inactivation-reactivation of aconitase in Escherichia coli. A sensitive measure of superoxide radical. J Biol Chem. 1992; 267:8757-8763. [PubMed: 1315737]

14. Gardner PR, Nguyen DD, White CW. Aconitase is a sensitive and critical target of oxygen poisoning in cultured mammalian cells and in rat lungs. Proc Natl Acad Sci U S A. 1994; 91:12248-12252. [PubMed: 7991614]

15. Gedik N, Maciel L, Schulte C, Skyschally A, Heusch G, Kleinbongard P. Cardiomyocyte mitochondria as targets of humoral factors released by remote ischemic preconditioning. Arch Med Sci. 2016; 13:448-458. [PubMed: 28261301]

16. Guo Y, Wu WJ, Qiu Y, Tang XL, Yang Z, Bolli R. Demonstration of an early and a late phase of ischemic preconditioning in mice. Am J Physiol. 1998; 275:H1375-1387. [PubMed: 9746488]

17. Heusch G, Musiolik J, Gedik N, Skyschally A. Mitochondrial STAT3 activation and cardioprotection by ischemic postconditioning in pigs with regional myocardial ischemia/ reperfusion. Circ Res. 2011; 109:1302-1308. [PubMed: 21980124]

18. Hinkle PC. P/O ratios of mitochondrial oxidative phosphorylation. Biochim Biophys Acta. 2005; 1706:1-11. [PubMed: 15620362]

19. Hurd TR, Requejo R, Filipovska A, Brown S, Prime TA, Robinson AJ, Fearnley IM, Murphy MP. Complex I within oxidatively stressed bovine heart mitochondria is glutathionylated on Cys-531 and Cys-704 of the 75-kDa subunit: potential role of CYS residues in decreasing oxidative damage. J Biol Chem. 2008; 283:24801-24815. [PubMed: 18611857]

20. Kang PT, Chen CL, Chen YR. Increased mitochondrial prooxidant activity mediates up-regulation of Complex I S-glutathionylation via protein thiyl radical in the murine heart of eNOS(-/-). Free Radic Biol Med. 2015; 79:56-68. [PubMed: 25445401]

21. Kang PT, Chen CL, Ohanyan V, Luther DJ, Meszaros JG, Chilian WM, Chen YR. Overexpressing superoxide dismutase 2 induces a supernormal cardiac function by enhancing redox-dependent mitochondrial function and metabolic dilation. J Mol Cell Cardiol. 2015b; 88:14-28. [PubMed: 26374996] 
22. Kang PT, Chen CL, Ren P, Guarini G, Chen YR. BCNU-induced gR2 defect mediates Sglutathionylation of Complex I and respiratory uncoupling in myocardium. Biochem Pharmacol. 2014; 89:490-502. [PubMed: 24704251]

23. Lacerda L, McCarthy J, Mungly SF, Lynn EG, Sack MN, Opie LH, Lecour S. TNFalpha protects cardiac mitochondria independently of its cell surface receptors. Basic Res Cardiol. 2010; 105:751-762. [PubMed: 20680307]

24. Lambert AJ, Brand MD. Superoxide production by NADH:ubiquinone oxidoreductase (complex I) depends on the $\mathrm{pH}$ gradient across the mitochondrial inner membrane. Biochem J. 2004; 382:511517. [PubMed: 15175007]

25. Lee HL, Chen CL, Yeh ST, Zweier JL, Chen YR. Biphasic modulation of the mitochondrial electron transport chain in myocardial ischemia and reperfusion. Am J Physiol Heart Circ Physiol. 2012; 302:H1410-1422. [PubMed: 22268109]

26. Lesnefsky EJ, Hoppel CL. Cardiolipin as an oxidative target in cardiac mitochondria in the aged rat. Biochim Biophys Acta. 2008; 1777:1020-1027. [PubMed: 18515061]

27. Lesnefsky EJ, Minkler P, Hoppel CL. Enhanced modification of cardiolipin during ischemia in the aged heart. J Mol Cell Cardiol. 2009; 46:1008-1015. [PubMed: 19303420]

28. Lesnefsky EJ, Slabe TJ, Stoll MS, Minkler PE, Hoppel CL. Myocardial ischemia selectively depletes cardiolipin in rabbit heart subsarcolemmal mitochondria. Am J Physiol Heart Circ Physiol. 2001; 280:H2770-2778. [PubMed: 11356635]

29. Liu B, Tewari AK, Zhang L, Green-Church KB, Zweier JL, Chen YR, He G. Proteomic analysis of protein tyrosine nitration after ischemia reperfusion injury: mitochondria as the major target. Biochim Biophys Acta. 2009; 1794:476-485. [PubMed: 19150419]

30. Paradies G, Paradies V, De Benedictis V, Ruggiero FM, Petrosillo G. Functional role of cardiolipin in mitochondrial bioenergetics. Biochim Biophys Acta. 2014; 1837:408-417. [PubMed: 24183692]

31. Paradies G, Petrosillo G, Pistolese M, Di Venosa N, Federici A, Ruggiero FM. Decrease in mitochondrial complex I activity in ischemic/reperfused rat heart: involvement of reactive oxygen species and cardiolipin. Circ Res. 2004; 94:53-59. [PubMed: 14656928]

32. Petrosillo G, Matera M, Moro N, Ruggiero FM, Paradies G. Mitochondrial complex I dysfunction in rat heart with aging: critical role of reactive oxygen species and cardiolipin. Free Radic Biol Med. 2009; 46:88-94. [PubMed: 18973802]

33. Ross T, Szczepanek K, Bowler E, Hu Y, Larner A, Lesnefsky EJ, Chen Q. Reverse electron flowmediated ROS generation in ischemia-damaged mitochondria: role of complex I inhibition vs. depolarization of inner mitochondrial membrane. Biochim Biophys Acta. 2013; 1830:4537-4542. [PubMed: 23747300]

34. Rottenberg H, Covian R, Trumpower BL. Membrane potential greatly enhances superoxide generation by the cytochrome bc1 complex reconstituted into phospholipid vesicles. J Biol Chem. 2009; 284:19203-19210. [PubMed: 19478336]

35. Sack MN. Mitochondrial depolarization and the role of uncoupling proteins in ischemia tolerance. Cardiovas Res. 2006; 72:210-219.

36. Scaduto RC Jr, Grotyohann LW. Measurement of Mitochondrial Membrane Potential Using Fluorescent Rhodamine Derivatives. Biophys J. 1999; 76:469-477. [PubMed: 9876159]

37. Vasquez-Vivar J, Kalyanaraman B, Kennedy MC. Mitochondrial aconitase is a source of hydroxyl radical. An electron spin resonance investigation. J Biol Chem. 2000; 275:14064-14069. [PubMed: 10799480]

38. Votyakova TV, Reynolds IJ. DeltaPsi(m)-Dependent and -independent production of reactive oxygen species by rat brain mitochondria. J Neurochem. 2001; 79:266-277. [PubMed: 11677254]

39. Zhang L, Chen CL, Kang PT, Garg V, Hu K, Green-Church KB, Chen YR. Peroxynitrite-mediated oxidative modifications of complex II: relevance in myocardial infarction. Biochemistry. 2010; 49:2529-2539. [PubMed: 20143804]

40. Zhang L, Yu L, Yu CA. Generation of superoxide anion by succinate-cytochrome c reductase from bovine heart mitochondria. J Biol Chem. 1998; 273:33972-33976. [PubMed: 9852050]

41. Zhao X, Chen YR, He G, Zhang A, Druhan LJ, Strauch AR, Zweier JL. Endothelial nitric oxide synthase (NOS3) knockout decreases NOS2 induction, limiting hyperoxygenation and conferring 
protection in the postischemic heart. Am J Physiol Heart Circ Physiol. 2007; 292:H1541-1550. [PubMed: 17114245]

42. Zhao X, He G, Chen YR, Pandian RP, Kuppusamy P, Zweier JL. Endothelium-derived nitric oxide regulates postischemic myocardial oxygenation and oxygen consumption by modulation of mitochondrial electron transport. Circulation. 2005; 111:2966-2972. [PubMed: 15939832] 
A

B

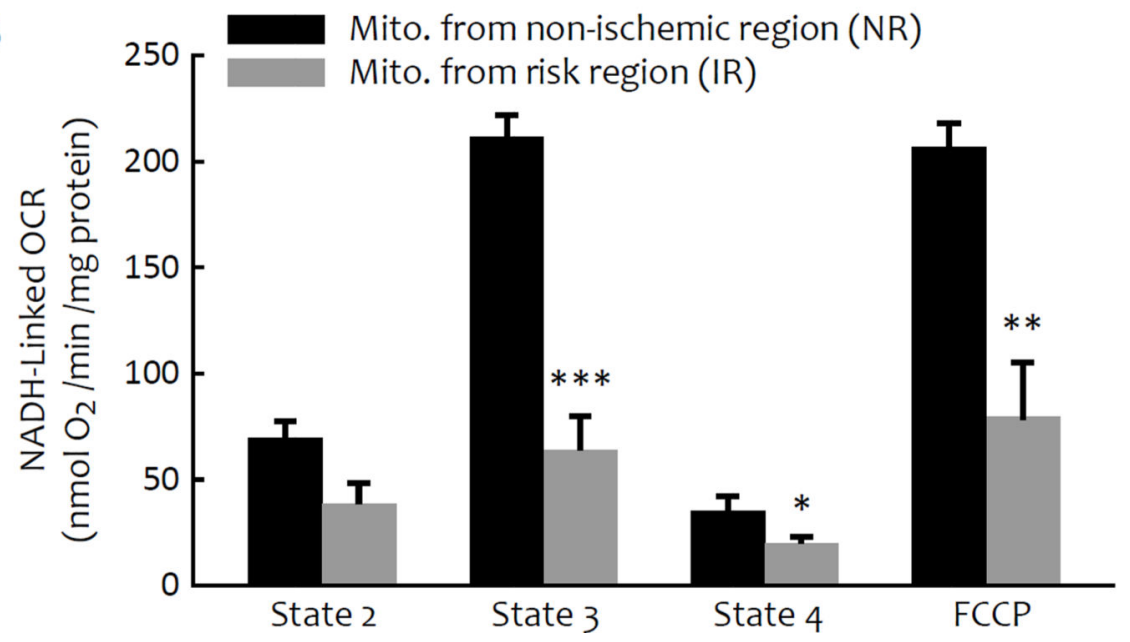

mito.+

glutamate + malate

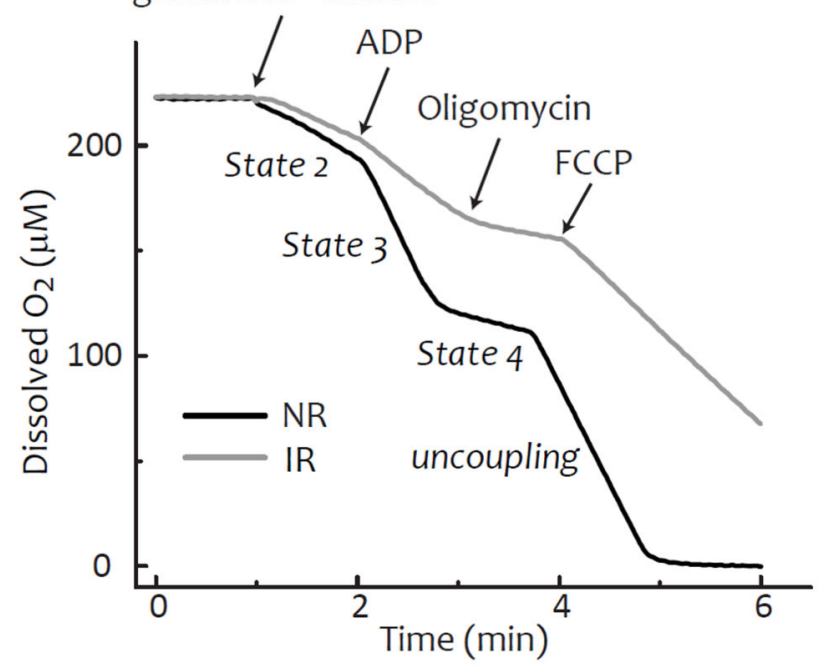

Figure 1.

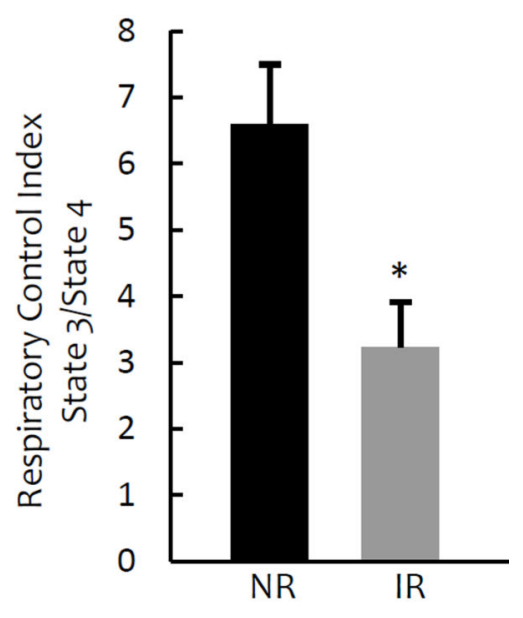

D

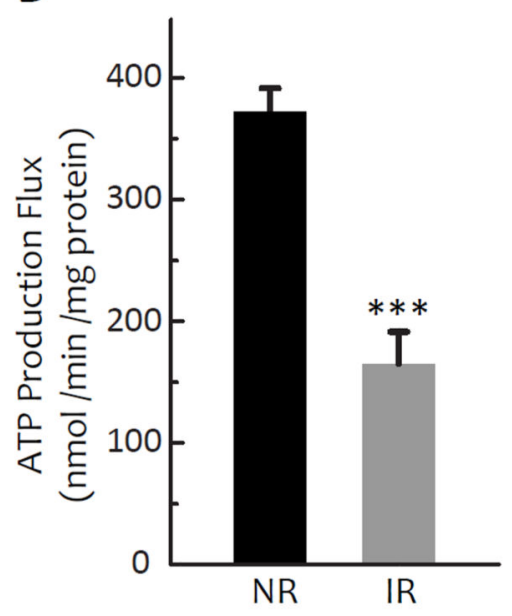

Mitochondria were prepared from the myocardia of non-ischemic (normal mitochondria, black bar) and risk regions (post-ischemic mitochondria, gray bar), and then subjected to measurement of the OCR by oxygen polarography at $30^{\circ} \mathrm{C}$ as described under “Experimental Procedures". A and B, state 3 (200 $\mu \mathrm{M}$ ADP used), state 4 ( $2 \mu \mathrm{g} / \mathrm{ml}$ oligomycin used), and FCCP (2.5 $\mu \mathrm{M}$ used)-mediated OCRs from the isolated mitochondria. $C$, Respiratory control index obtained from the ratio of state 3 OCR to state 4 OCR. $n=6$; $* * p<0.01$, assessed by Student's $t$-test for normal mitochondria (NR) vs post-ischemic mitochondria (IR) in $\boldsymbol{A}$ and $\boldsymbol{B} . \boldsymbol{D}$, ATP production flux mediated by normal and postischemic mitochondria, $n=4 ; * * p<0.01$. 
A

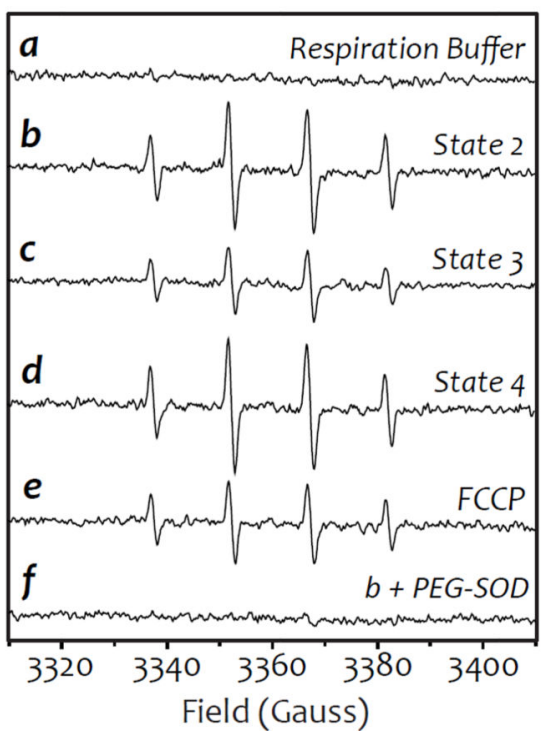

B

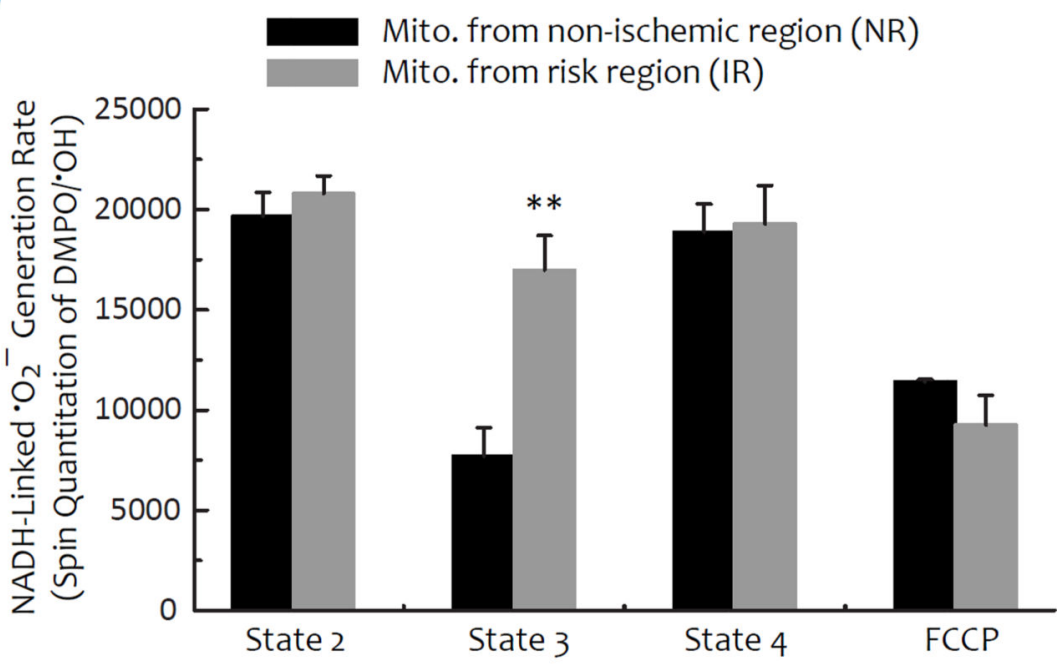

Figure 2.

The ${ }^{\circ} \mathrm{O}_{2}{ }^{-}$generation mediated by mitochondria in the presence of glutamate and malate [in $\mathrm{mM}$, potassium glutamate (140) and malate (5), NADH-linked] was assessed by EPR spin trapping with DMPO according to our published methods [22]. $\boldsymbol{A}$, the EPR spectra of the SOD-sensitive DMPO/ ${ }^{\circ} \mathrm{OH}$ adduct mediated by normal mitochondria under the conditions of state 2 ( spectrum b), state 3 ( spectrum c), state 4 ( spectrum d), FCCP uncoupling (spectrum e), and the effect of PEG-SOD on the detected DMPO/ ${ }^{\circ} \mathrm{OH}$ adducts (spectrum f) $\boldsymbol{B}$, Comparison between two groups of normal mitochondria (NR, gray bar) and post-ischemic mitochondria (IR, black bar) in the mediation of NADH-linked ${ }^{\circ} \mathrm{O}_{2}{ }^{-}$generation (state 2, state 3, state 4, and FCCP). Data were collected based on spin quantitation of DMPO/ ${ }^{\circ} \mathrm{OH}$. Data were analyzed by Student's $t$-test $(n=6, * * p<0.01)$. 

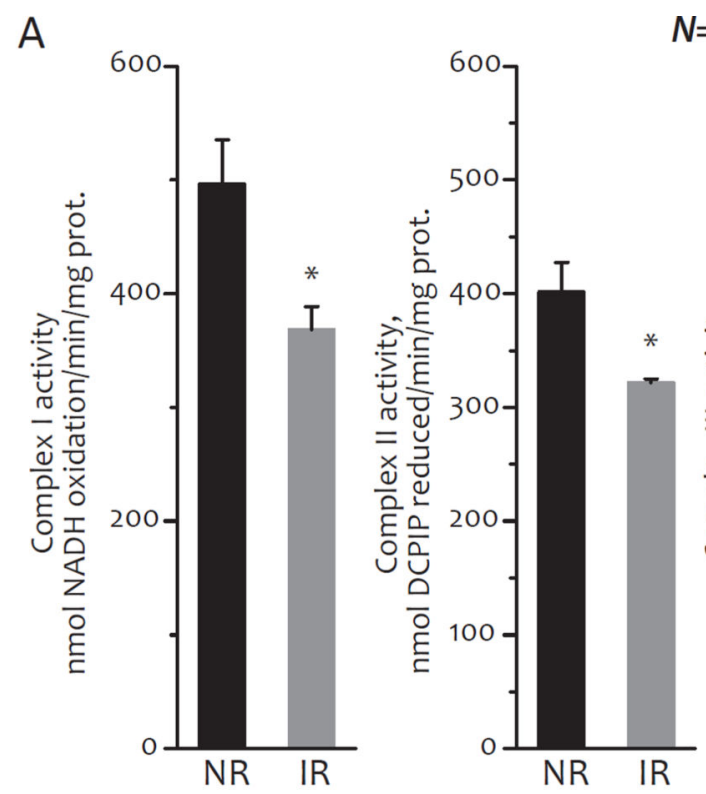

$N=4$
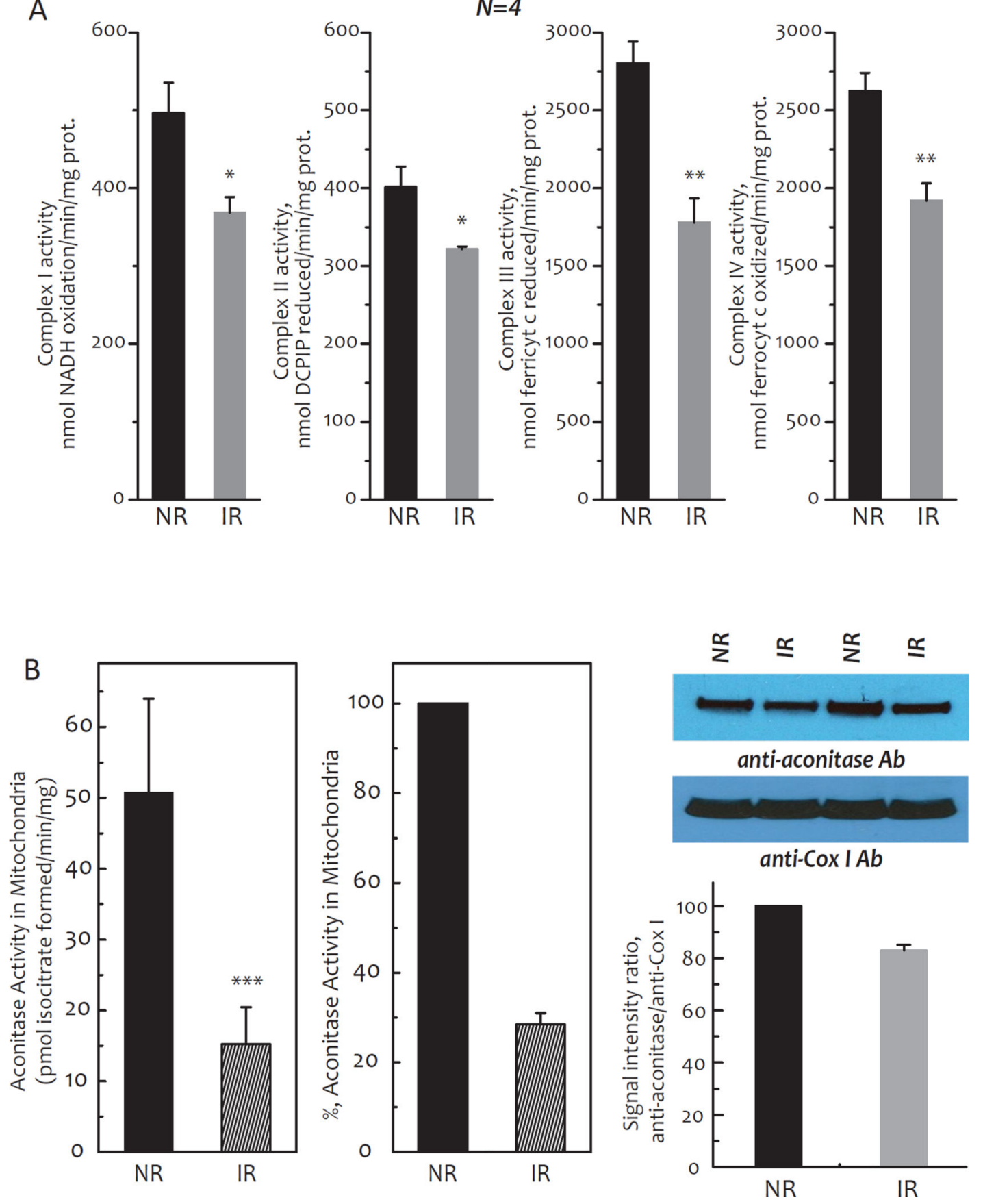

Figure 3.

Mitochondria were isolated from the non-ischemic region (NR) and the risk region (IR), permeabilized by alamethicin ( $40 \mathrm{mg}$ protein: $1 \mathrm{mg}$ alamathicin ratio), and then subjected to assay. $\boldsymbol{A}$, The enzymatic activities of ETC components in the mitochondria were assayed as described previously $[22,25]$ (NR vs IR, $n=4, * p<0.05$ ). $\boldsymbol{B}$, The enzymatic activity of aconitase was measured as described previously [20] (NR vs IR, $n=4$, *** $p<0.001$ ). Mitochondrial preparation (100 $\mu \mathrm{g}$ protein per lane) was probed with a polyclonal antibody against aconitase (1:500), and the subunit I of complex IV (anti-Cox I, 1:4,000) was used as 
the loading control. Data were normalized to the signal intensity of mitochondrial complex IV. 
A

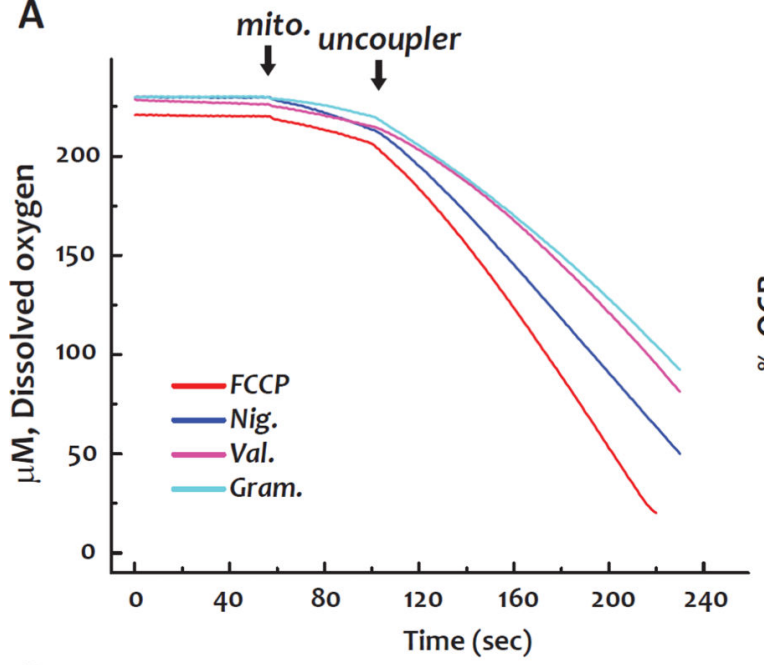

B

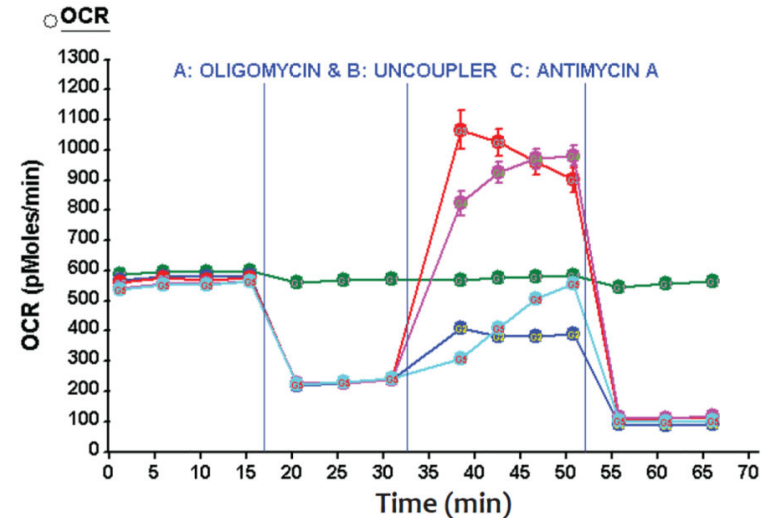

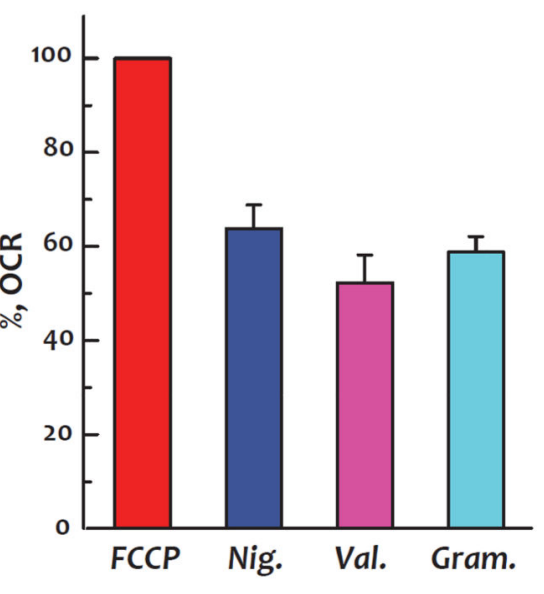
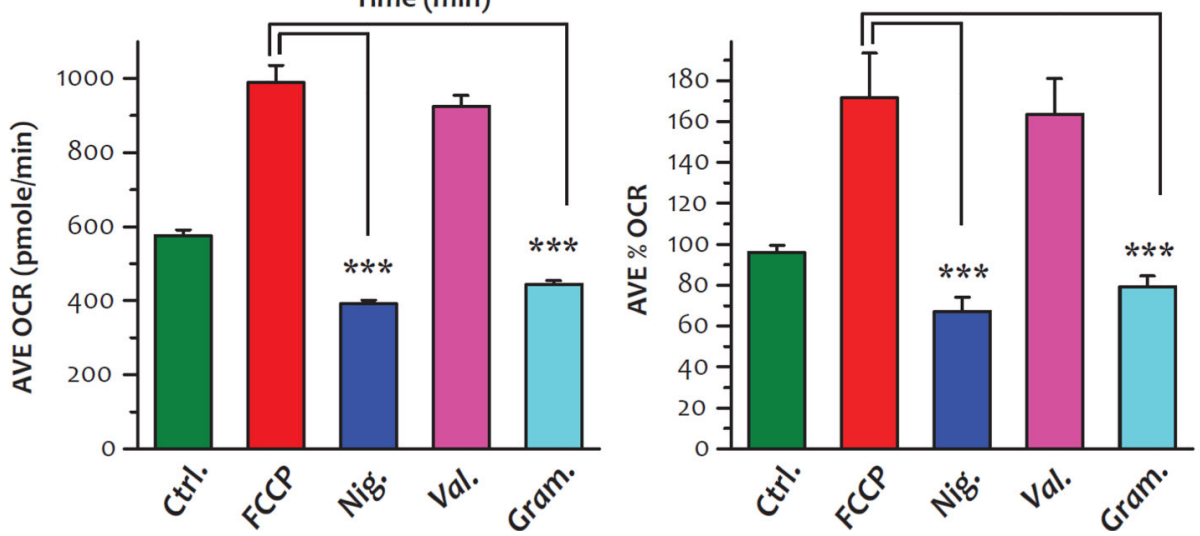

Figure 4.

The mitochondria were isolated from the non-ischemic region (NR) and the risk region (IR), and then subjected to measurement of OCR using an oxygen polarograph at $30^{\circ} \mathrm{C}$. The mitochondrial preparation $(0.5 \mathrm{mg} / \mathrm{ml})$ was added to an NADH-linked respiration buffer containing malate plus glutamate to initiate oxygen consumption. The OCR was then enhanced by an uncoupler. $\boldsymbol{A}$, The OCRs of normal mitochondrial preparations $(0.5 \mathrm{mg} / \mathrm{ml})$ were enhanced by uncoupling with FCCP $(2.5 \mu \mathrm{M})$, nigericin $(5 \mu \mathrm{M})$, valinomcin $(180 \mathrm{nM})$, and gramicidine $(2 \mu \mathrm{g} / \mathrm{mL})(n=3)$. $\boldsymbol{B}$, Upper panel, the chart of extracellular flux analysis 
showing measurements of the percentage changes of OCR of HL-1 cells after compound injections. After oligomycin (port A) inhibition of ATP-linked oxygen consumption, various uncouplers (nigericin, FCCP, valinomycin, or gramicidin; port B) were injected into the microplate to induce oxygen consumption. The enhanced OCRs were attributed to $\Delta p, \Delta \mathrm{pH}$, or $\Delta \Psi$ according to the nature of the uncouplers. The final injection of antimycin A (port C) inhibited the relative mitochondrial oxygen consumption and resulted in the same percentage of non-mitochondrial OCR, confirming that the effects of the uncouplers targeted mitochondria directly, and that this effect could be abolished by antimycin A. Lower panel, the average \%OCR of various uncouplers was calculated based on the measurement in the graph in the upper panel. In the control group (Ctrl), the \% OCR remained above $90 \%$ after three mock injections of assay medium, which served as an additional control indicating that the HL-1 cells remained viable throughout the two hours of the assay time. Nig., nigericin; Val., valinomycin; Gram., gramicidin; $n=6, * * * p<0.001$. 


\section{Mitochondria from the myocardium of non-ischemic region (NR)}

Mitochondria from the myocardium of risk region (IR)
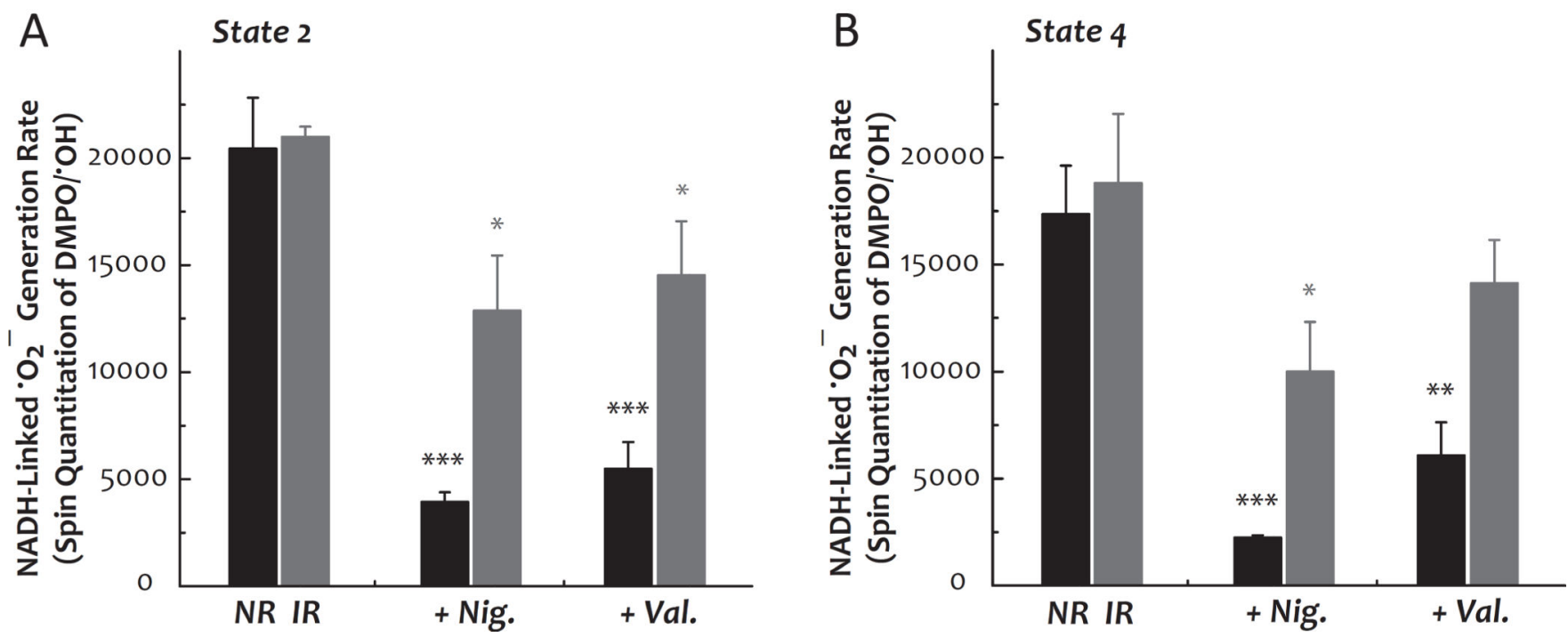

Figure 5.

Effects of nigericin and valinomycin on the NADH-linked ${ }^{\circ} \mathrm{O}_{2}^{-}$generation mediated by the mitochondria isolated from the non-ischemic region (NR) and the risk region (IR). The assay was conducted under state 2 (in $\boldsymbol{A}$ ) and state 4 (in $\boldsymbol{B}$ ) respiratory conditions. Mitochondria $(0.5 \mathrm{mg} / \mathrm{ml})$ isolated from the non-ischemic myocardium or from the risk region of the postischemic myocardium were pre-treated with nigericin $(5 \mu \mathrm{M})$ or valinomycin $(4 \mu \mathrm{g} / \mathrm{mL})$ prior to EPR assay. The ${ }^{\bullet} \mathrm{O}_{2}^{-}$generation mediated by as-isolated or nigericin-treated or valinomycin-treated mitochondria in the presence of glutamate and malate (NADH-linked) was assessed by EPR spin trapping with DMPO according to our published methods [22]. Data were collected based on spin quantitation of DMPO/ ${ }^{\circ} \mathrm{OH}$ adducts and by comparisons among three groups of NR or IR, nigericin treatment (+Nig.) and valinomycin treatment (+Val.). $n=4, * * * p<0.001$ for NR vs NR+Nig or NR+Val. (state 2 ), and NR vs NR+Nig. (state 4$) ; * * p<0.01$ for NR vs NR+Val. (state 4$) ; * p<0.05$ for IR vs IR+Nig or IR+Val. (state 2), and IR vs IR+Nig. (state 4). 

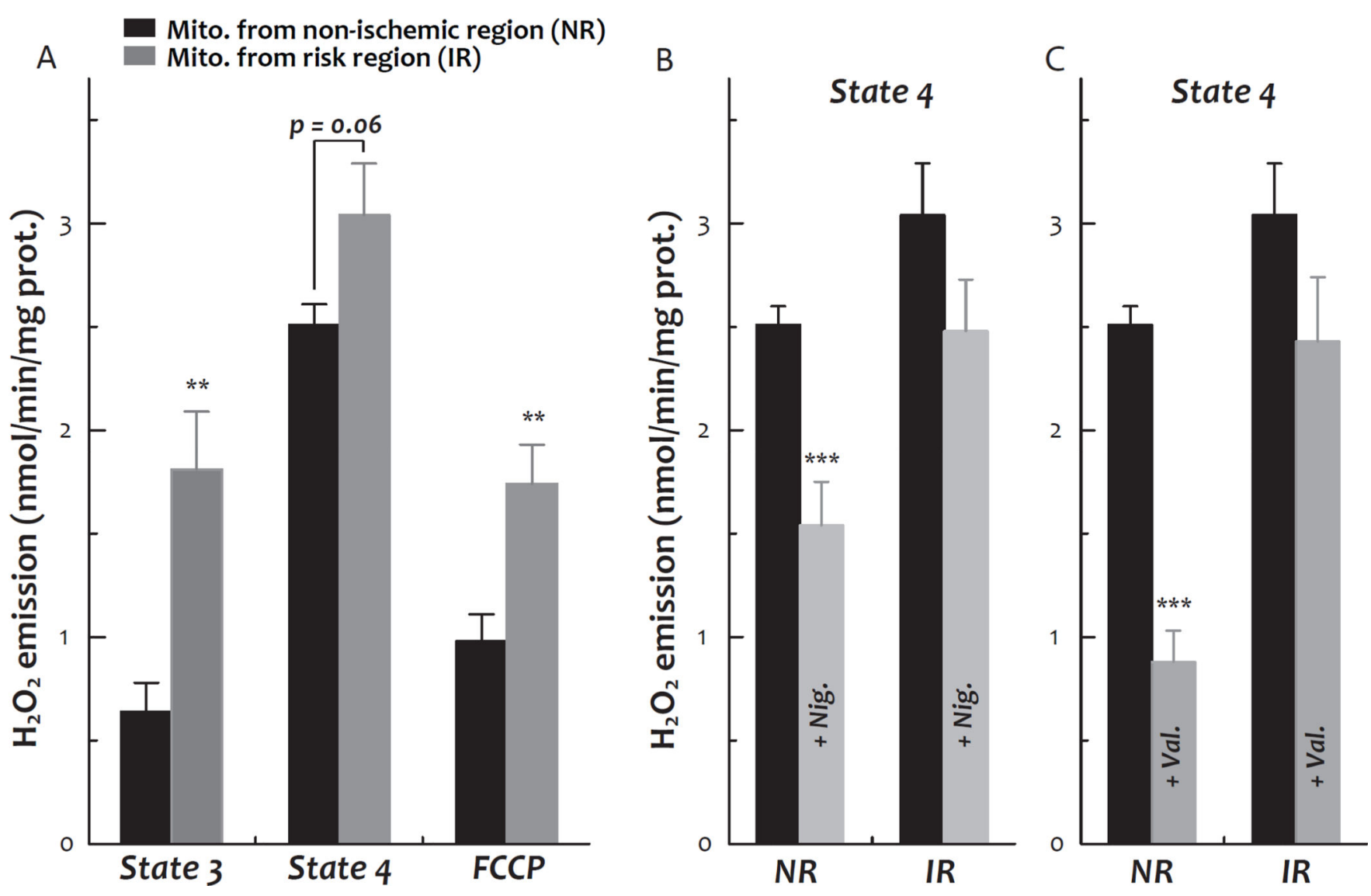

Figure 6.

$A$, The rates of $\mathrm{H}_{2} \mathrm{O}_{2}$ generation mediated by the mitochondria of non-ischemic and risk regions in the presence of glutamate and malate (NADH-linked) under state 3, state 4 , and FCCP-uncoupling conditions were assessed by an HRP/Amplex Red assay $(n=8) . \boldsymbol{B}-\boldsymbol{C}$, the effects of nigericin (Nig.) and valinomycin (Val.) on $\mathrm{H}_{2} \mathrm{O}_{2}$ generation rates mediated by the normal mitochondria and the post-ischemic mitochondria $(n=8, * * p<0.01 ; * * *<0.001)$. 
A

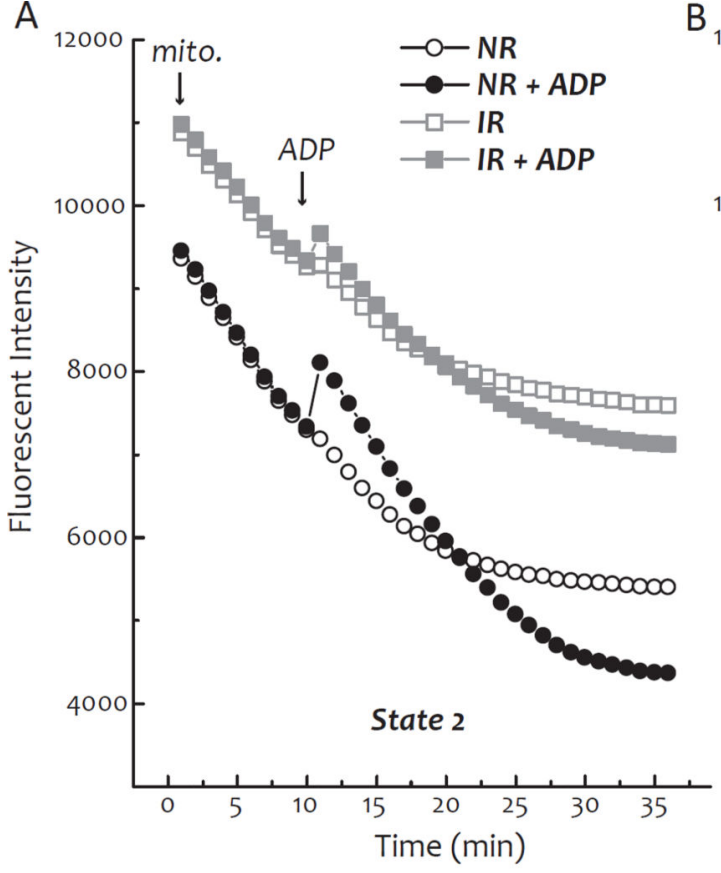

C

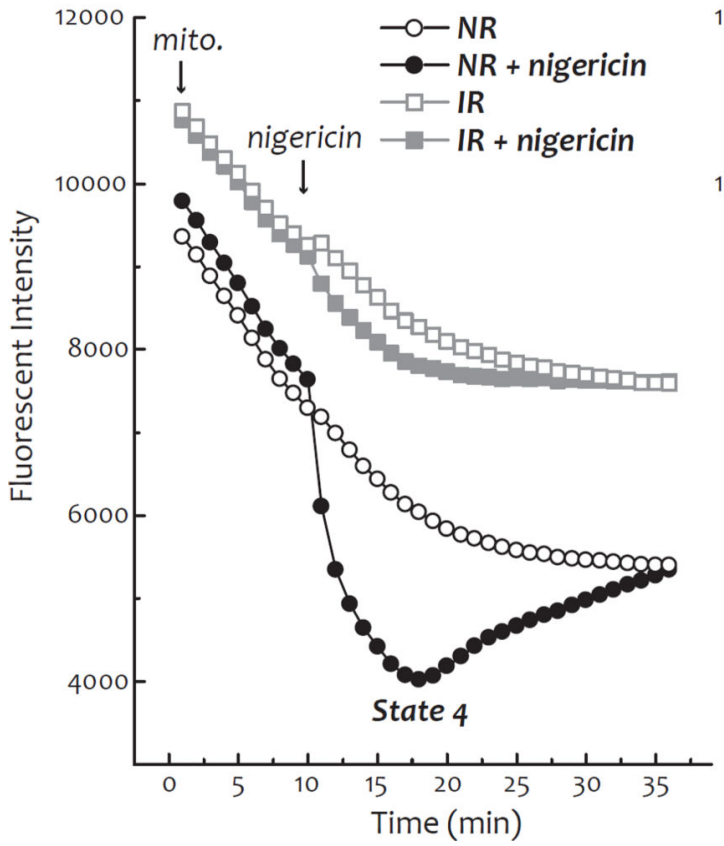

$B$

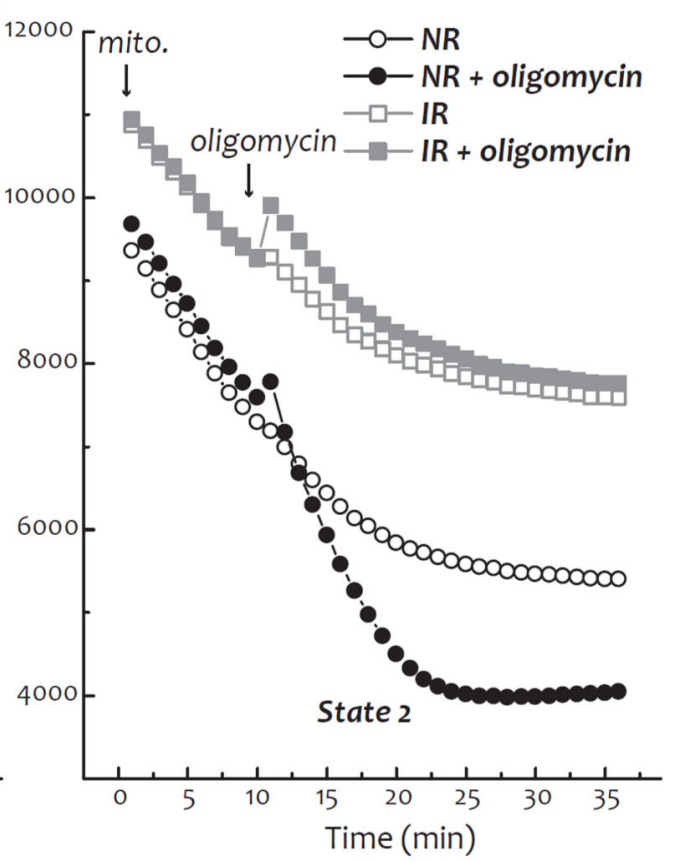

D

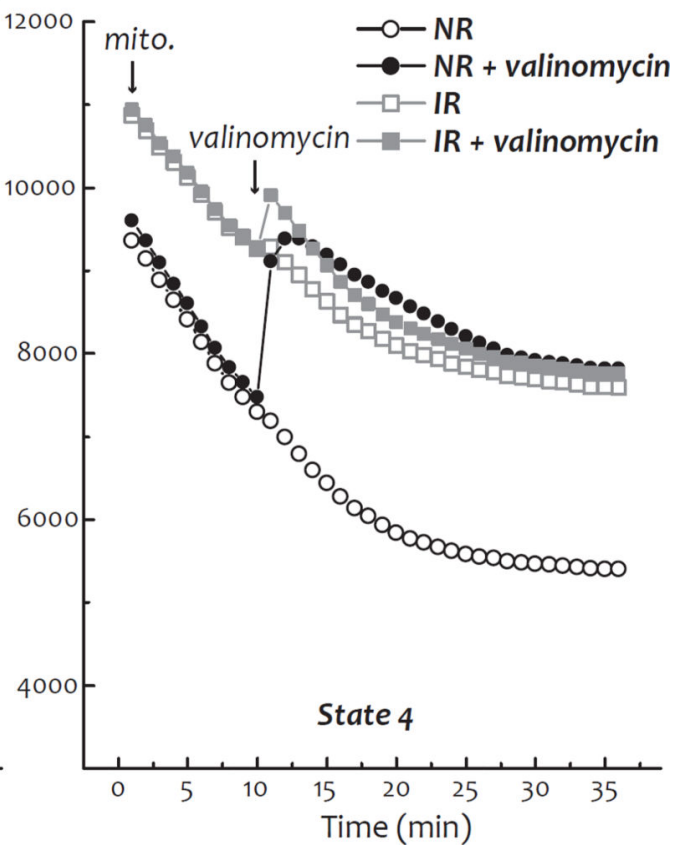

Figure 7.

The mitochondria were isolated from the non-ischemic region (NR) and the risk region (IR), and then subjected to measurement of $\Delta \psi$ using a fluorescent probe, TMRM, as described in the experimental procedure. $A$, measurement of $\Delta \psi$ under state 3 conditions in the presence of ADP; $B$, measurement of $\Delta \psi$ under state 4 conditions in the presence of oligomycin; $C$, measurement of $\Delta \psi$ under state 4 conditions in the presence of nigericin; $D$, measurement of $\Delta \psi$ under state 4 conditions in the presence of valinomycin. Each data point was collected from the average of three repeats $(n=3)$. 
A

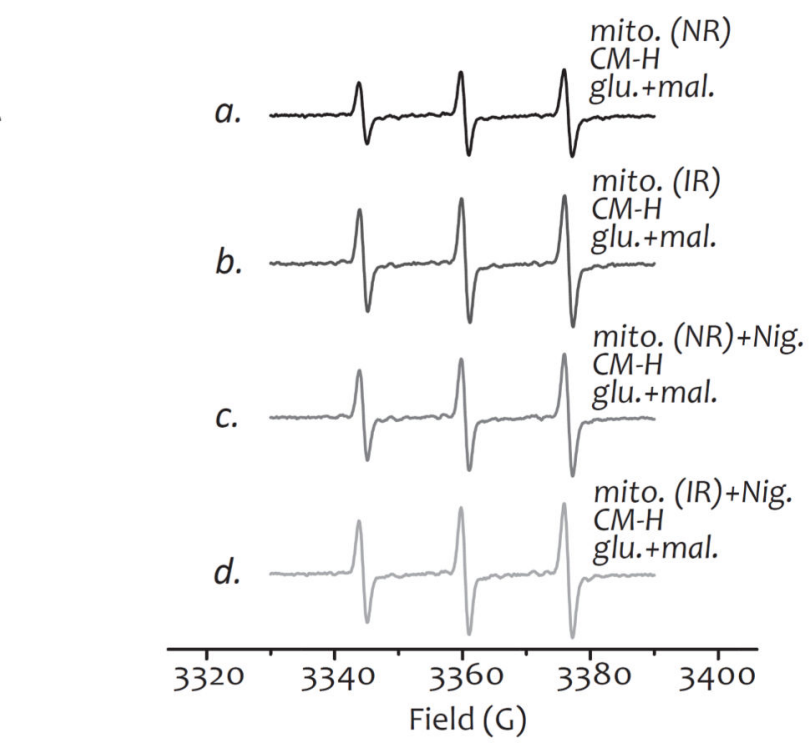

B

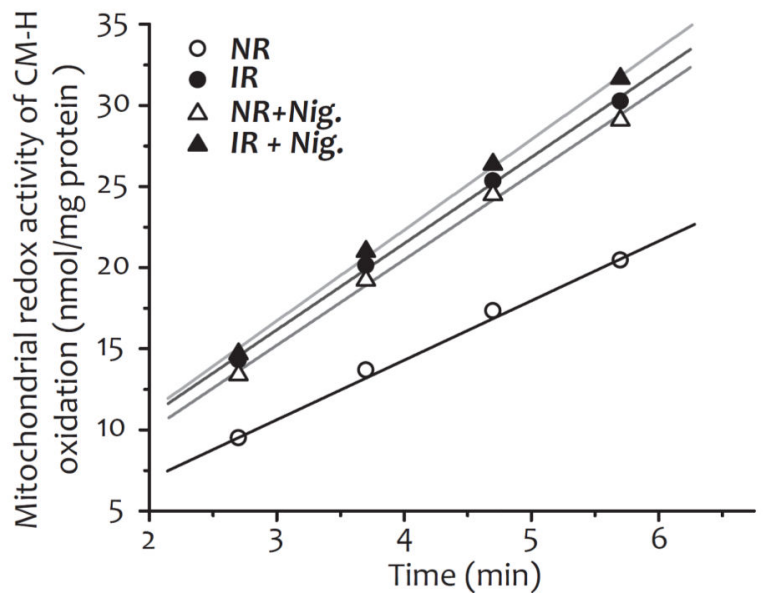

C

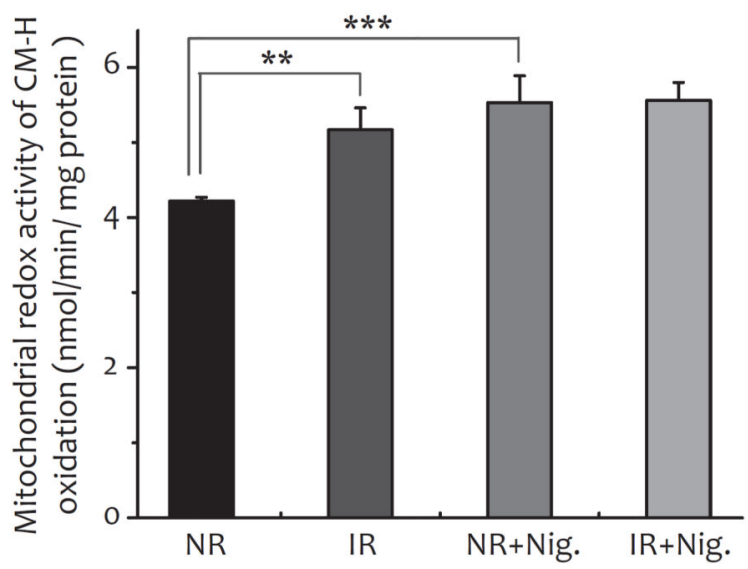

D

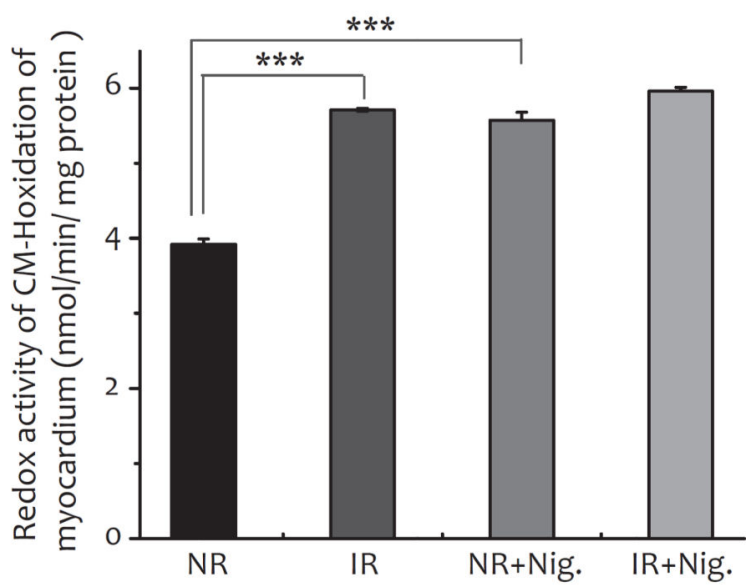

Figure 8. The effect of nigericin in the redox activity of CM-H oxidation mediated by the isolated mitochondria (in $A-C$ ) and tissue homogenate of post-ischemic myocardium (in $D$ )

$A$, mitochondria $(0.4 \mathrm{mg} / \mathrm{ml})$ isolated from the non-ischemic region (NR in $a)$ and the risk region (IR in $b$ ) in respiration buffer (in $\mathrm{mM}, \mathrm{NaCl} 10, \mathrm{MgCl}_{2} 1$, EGTA 1 , Trizma 1 , phosphate 2.5 , and cytochrome $c 0.01$; adjusted to $\mathrm{pH} 7.4$ ) containing $1 \mathrm{mM}$ DTPA were incubated with $\mathrm{CM}-\mathrm{H}(1 \mathrm{mM})$ at room temperature. Oxidation of $\mathrm{CM}-\mathrm{H}$ was immediately initiated by glutamate plus malate [(glu. plus mal.), $140 \mathrm{mM} / 5 \mathrm{mM}$ ] and then subjected to EPR measurement. To assess the effect of nigericin (Nig. in $c$ and $d$ ), the mitochondrial preparation was pre-treated with nigericin (Nig., $5 \mu \mathrm{M}$ ) prior to $\mathrm{CM}-\mathrm{H}$ incubation, activation of glutamate and malate, and EPR measurement. $\boldsymbol{B}$, same as A, except that the redox activity of converting CM-H to a stable nitroxide is presented in a kinetic curve. $\boldsymbol{C}$, same as A, except that the redox activity of converting CM-H to a stable nitroxide is presented in a bar graph $(n=5, * * p<0.01$ and $* * * p<0.001)$. $\boldsymbol{D}$, The tissue homogenates $(0.25 \mathrm{mg} / \mathrm{ml})$ of the non-ischemic region and the risk region excised from the post-ischemic myocardium in NADH-linked respiration buffer containing $1 \mathrm{mM}$ DTPA, $140 \mathrm{mM}$ glutamate, $5 \mathrm{mM}$ malate, and $1 \mathrm{mM} \mathrm{CM}-\mathrm{H}$ were subjected to EPR measurement for converting the hydroxylamine to a stable nitroxide $(n=5, * * p<0.01$ and $* * * p<0.001)$. The instrumental settings used for 
detecting the three-line spectrum of the nitroxide are: center field, $3360.3 \mathrm{G}$; sweep width, $60 \mathrm{G}$; microwave frequency, $9.43 \mathrm{GHz}$; power, $20 \mathrm{~mW}$; receiver gain, $5.02 \times 10^{3}$; modulation frequency, 100kHz; modulation amplitude, $1 \mathrm{G}$; time constant, $163.84 \mathrm{~ms}$; conversion time, $41 \mathrm{~ms}$; sweep time, $42 \mathrm{sec}$; number of X-scans, 1. 
Mitochondria

Mitochondria + Nigericin

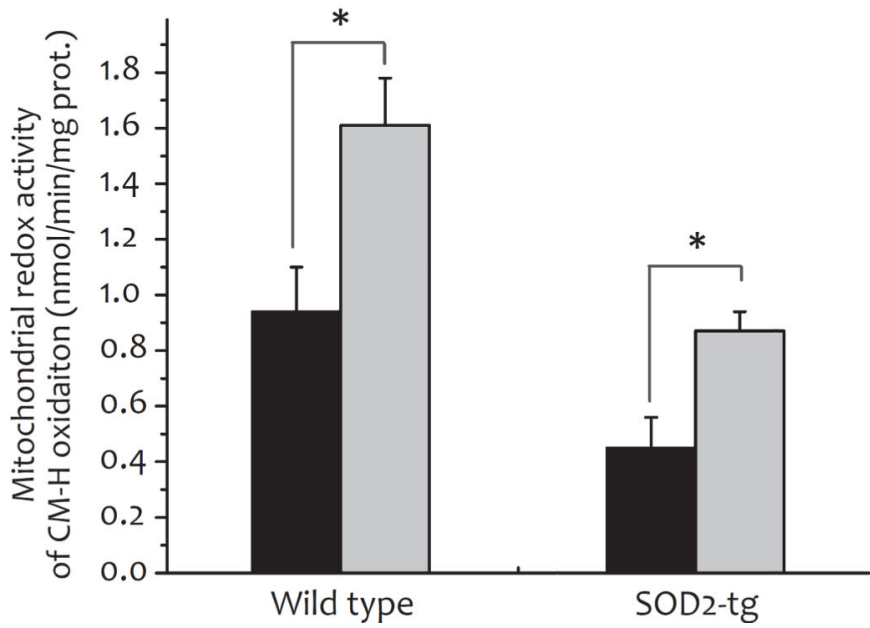

Mitochondria

Mitochondria + Nigericin

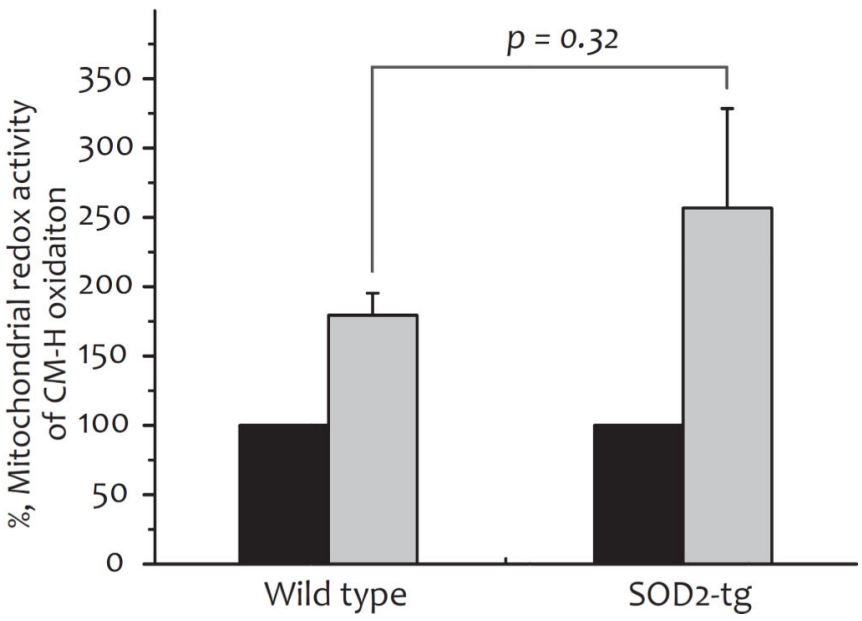

Figure 9. The effect of nigericin in the redox activity of CM-H oxidation mediated by the mitochondria isolated from the myocardium of wild type and SOD2-tg mice

Mitochondria $(0.4 \mathrm{mg} / \mathrm{ml})$ isolated from the myocardium of wild type and SOD2-tg mice ( 27-33 g and 12 weeks old) in respiration buffer (as indicated in the legend of Figure 6) containing $1 \mathrm{mM}$ DTPA and $1 \mathrm{mM} \mathrm{CM}-\mathrm{H}$ were subjected to EPR measurement at $298 \mathrm{~K}$. To assess the effect of nigericin (in gray bar), the mitochondrial preparation was pre-treated with nigericin (Nig., $5 \mu \mathrm{M}$ ) prior to $\mathrm{CM}-\mathrm{H}$ incubation prior to EPR measurement. The instrumental EPR parameters were the same as described in the legend of Figure $5(n=5, * p$ $<0.05)$. 

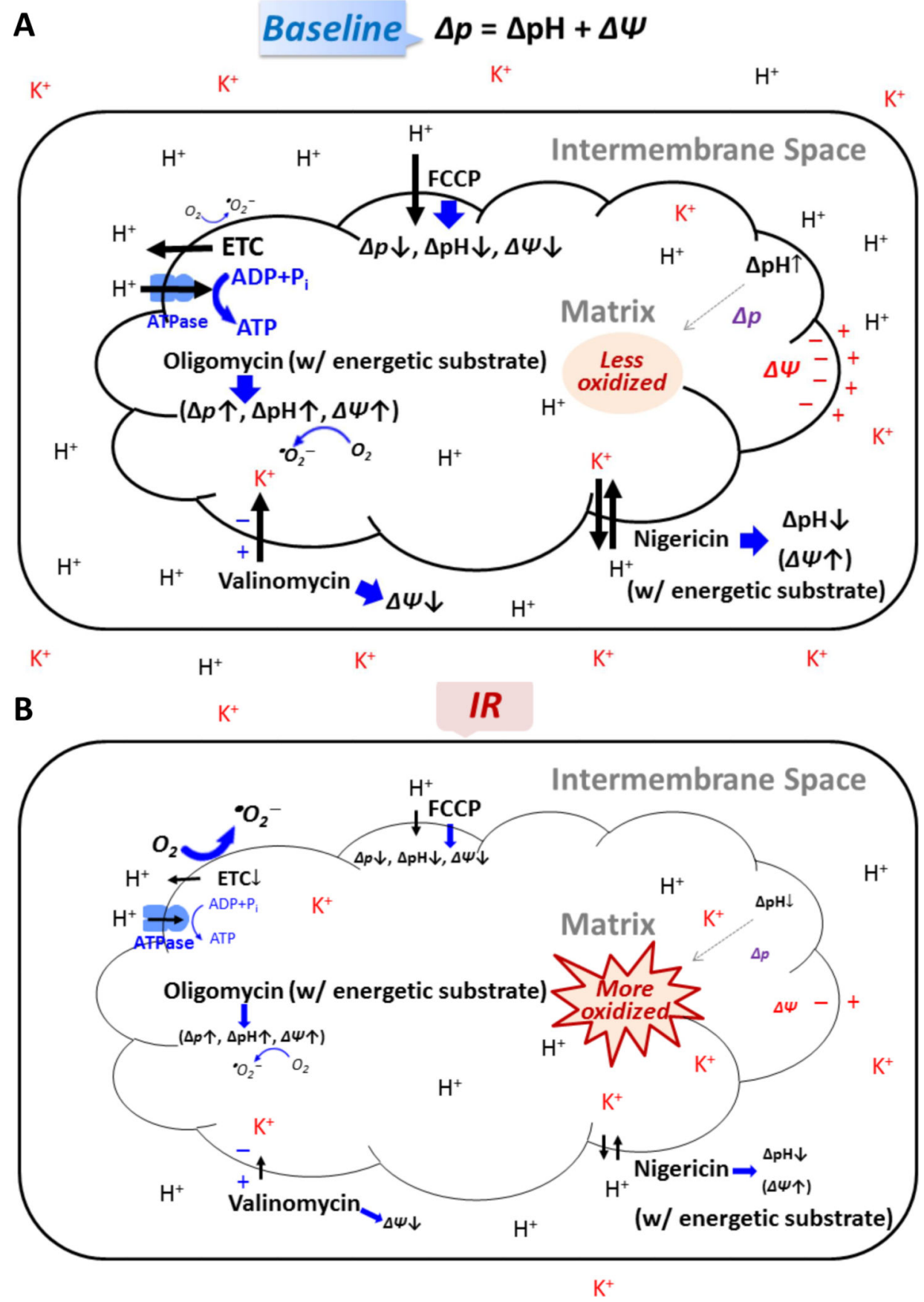

Figure 10. Diagram showing the mechanism by which $\mathrm{pH}$ gradient $(\Delta \mathrm{pH})$ and membrane potential $(\Delta \Psi)$ mediates redox dysfunction-associated post-ischemic injury in the mitochondria of rat heart

$A$, under the basal conditions, electron flow mediated by ETC is accompanied by the transmembrane movement of protons to generate $\Delta \mathrm{pH}$ and $\Delta \Psi$. The proton motive force (pmf) derived from electrochemical gradient $(\Delta p)$ pushes the protons to re-enter the matrix through $\mathrm{F}_{\mathrm{i}} \mathrm{F}_{0} \mathrm{ATPase}$ (ATPase, denoted by blue rectangle-oval object) for ATP synthesis. The presence of ADP (state 3 conditions) minimizes the electron leakage for ${ }^{\circ} \mathrm{O}_{2}{ }^{-}$generation by ETC. Oligomycin blocks the proton channel of ATPase, thus enhancing the $\Delta \mathrm{pH}$ and $\Delta \Psi$ of 
normal mitochondria (indicated by thick arrows). The higher $\Delta \mathrm{pH}$ and $\Delta \Psi$ of normal mitochondria as the source of electron leakage for ${ }^{\circ} \mathrm{O}_{2}{ }^{-}$generation are highly sensitive to nigericin and valinimyicn. The higher $\mathrm{pH}$ and $\Delta \Psi$ also predisposes the mitochondria to a less oxidized physiological setting (dashed arrow). $\boldsymbol{B}$, in comparison to basal conditions, myocardial ischemia and reperfusion (IR) induced oxidative damage of ETC and subsequently impaired $\Delta \mathrm{pH}$ and $\Delta \Psi$, which further decreases the proton motive force for ATP synthesis. Oxidative injury of ETC also greatly enhances the electron leakage for ${ }^{\circ} \mathrm{O}_{2}{ }^{-}$ generation in the post-ischemic mitochondria. Due to IR-induced impairment of pmf and ATPase, the electron leakage for ${ }^{\circ} \mathrm{O}_{2}{ }^{-}$generation driven by $\Delta \mathrm{pH}$ and $\Delta \Psi$ is less sensitive to oligomycin, nigericin, and valinomycin (indicated by fine arrows). The impairment of $\Delta \mathrm{pH}$ by IR further predisposes post-ischemic mitochondria to a more oxidized physiological setting (dashed arrow). 


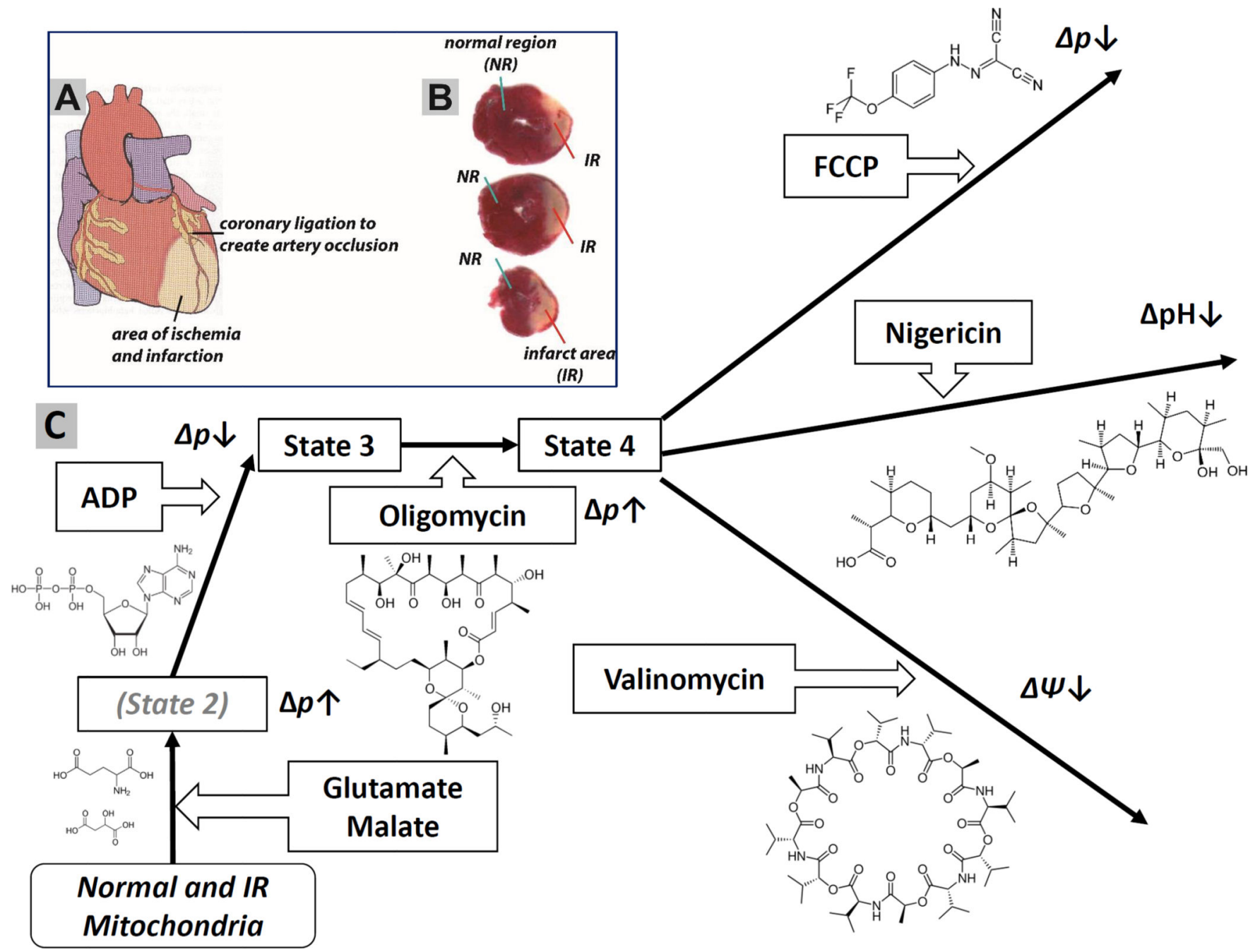

Scheme 1.

$\boldsymbol{A}$, the approach to construct the model of in vivo myocardial ischemia and reperfusion rat heart as described in the Experimental Procedures; $\boldsymbol{B}$, TCC staining of the infarct area or the risk region in the post-ischemic myocardium. $\boldsymbol{C}$, Strategic design to assess the $\Delta p H$ and $\Delta \Psi$ of mitochondria. Mitochondria were isolated from the myocardium of non-ischemic region (NR or normal mitochondria) and infarct region (IR or post-ischemic mitochondria). The substrate of glutamate plus malate was used to induce state 2 NADH-linked oxygen consumption. The electrochemical gradient, $\Delta p$, was increased because $\Delta p H$ was established and proton circuit is not completed by $\mathrm{H}^{+}$re-entry through the ATPase (ATP synthase). The addition of ADP was used to induce state 3 oxygen consumption, allowing the ATPase to synthesize ATP coupled to $\mathrm{H}^{+}$re-entry across the membrane through the proton channel of ATPase, $\Delta p$ was thus decreased. Oligomycin was used to block the proton channel of ATPase and induce state 4 oxygen consumption. $\Delta p$ was thus enhanced due to reestablishment of the proton gradient. Proton ionophore, FCCP, was used to dissipate protein gradient and membrane potential, allowing $\Delta p$ diminishment. Nigericine was used to 
enhance proton influx and dissipate $\Delta \mathrm{pH}$. Potassium ionophore, valinomycin, was used to dissipate the membrane potential. 